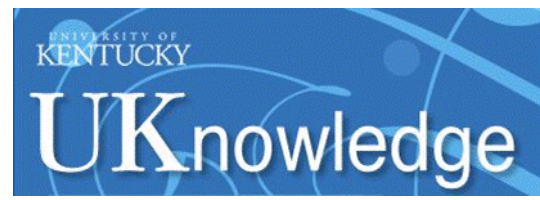

University of Kentucky

UKnowledge

Theses and Dissertations--Educational, School, and Counseling Psychology

Educational, School, and Counseling

Psychology

2019

\title{
MEASURING POLICE OFFICER SELF-EFFICACY FOR WORKING WITH INDIVIDUALS WITH AUTISM SPECTRUM DISORDER
}

\author{
Abigail M. A. Love \\ University of Kentucky, amlove2@uky.edu \\ Author ORCID Identifier: \\ (iD) https://orcid.org/0000-0002-6647-9814 \\ Digital Object Identifier: https://doi.org/10.13023/etd.2019.385
}

Right click to open a feedback form in a new tab to let us know how this document benefits you.

\section{Recommended Citation}

Love, Abigail M. A., "MEASURING POLICE OFFICER SELF-EFFICACY FOR WORKING WITH INDIVIDUALS WITH AUTISM SPECTRUM DISORDER" (2019). Theses and Dissertations--Educational, School, and Counseling Psychology. 89.

https://uknowledge.uky.edu/edp_etds/89

This Doctoral Dissertation is brought to you for free and open access by the Educational, School, and Counseling Psychology at UKnowledge. It has been accepted for inclusion in Theses and Dissertations--Educational, School, and Counseling Psychology by an authorized administrator of UKnowledge. For more information, please contact UKnowledge@lsv.uky.edu. 


\section{STUDENT AGREEMENT:}

I represent that my thesis or dissertation and abstract are my original work. Proper attribution has been given to all outside sources. I understand that I am solely responsible for obtaining any needed copyright permissions. I have obtained needed written permission statement(s) from the owner(s) of each third-party copyrighted matter to be included in my work, allowing electronic distribution (if such use is not permitted by the fair use doctrine) which will be submitted to UKnowledge as Additional File.

I hereby grant to The University of Kentucky and its agents the irrevocable, non-exclusive, and royalty-free license to archive and make accessible my work in whole or in part in all forms of media, now or hereafter known. I agree that the document mentioned above may be made available immediately for worldwide access unless an embargo applies.

I retain all other ownership rights to the copyright of my work. I also retain the right to use in future works (such as articles or books) all or part of my work. I understand that I am free to register the copyright to my work.

\section{REVIEW, APPROVAL AND ACCEPTANCE}

The document mentioned above has been reviewed and accepted by the student's advisor, on behalf of the advisory committee, and by the Director of Graduate Studies (DGS), on behalf of the program; we verify that this is the final, approved version of the student's thesis including all changes required by the advisory committee. The undersigned agree to abide by the statements above.

Abigail M. A. Love, Student

Dr. Ellen L. Usher, Major Professor

Dr. Michael Toland, Director of Graduate Studies 


\title{
MEASURING POLICE OFFICER SELF-EFFICACY FOR WORKING WITH INDIVIDUALS WITH AUTISM SPECTRUM DISORDER
}

\author{
DISSERTATION \\ A dissertation submitted in partial fulfillment of the \\ Requirements for the degree of Doctor of Philosophy in the \\ College of Education \\ at the University of Kentucky \\ By \\ Abigail M. A. Love \\ Lexington, Kentucky \\ Director: Dr. Ellen L. Usher, Professor of Educational Psychology \\ Lexington, Kentucky \\ 2019
}

Copyright $($ ) Abigail M. A. Love 2019 


\title{
ABSTRACT OF DISSERTATION \\ MEASURING POLICE OFFICER SELF-EFFICACY FOR WORKING WITH INDIVIDUALS WITH AUTISM SPECTRUM DISORDER
}

\begin{abstract}
Autism spectrum disorder (ASD) is currently one of the most researched of all childhood developmental disorders and is receiving attention in many domains including popular media, social sciences, education, and medicine. The purpose of this dissertation was to design and provide initial psychometric evidence for a scale that measures police officer self-efficacy for working with individuals with ASD. Psychometric properties of a scale designed to measure knowledge of ASD were also explored. Data from 620 police officers actively serving in the United States were collected in two separate phases. A 13item scale was created to measure police officer self-efficacy for working with individuals with ASD. Results from both phases indicated that the scale represented a unidimensional construct. Police officer knowledge of ASD was significantly and positively related to self-efficacy. Knowing more about officers' knowledge and beliefs in their own capabilities to work with individuals with ASD can help inform future police education and training efforts.
\end{abstract}

KEYWORDS: Police officer, self-efficacy, autism spectrum disorder, scale development, psychometrics

Abigail M. A. Love

Student's Signature

July 22, 2019

Date 


\section{MEASURING POLICE OFFICER SELF-EFFICACY FOR WORKING WITH INDIVIDUALS WITH AUTISM SPECTRUM DISORDER}

By

Abigail M. A. Love

Dr. Ellen L. Usher, PhD Director of Dissertation

Dr. Michael Toland, PhD Director of Graduate Studies

July 22, 2019

Date 
Dedicated to Sarah, Sam, and Miles - my companions and motivation for this journey. 


\section{TABLE OF CONTENTS}

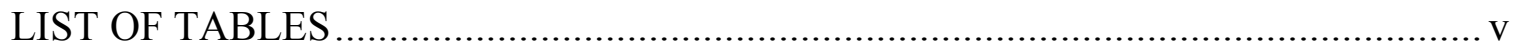

LIST OF FIGURES ................................................................................. vi

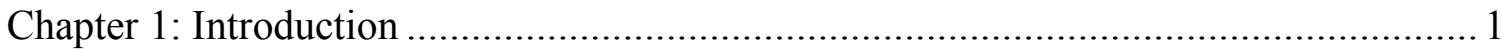

Chapter 2: Theoretical Framework and Literature Review ..................................... 4

Social Cognitive Theory ................................................................................ 4

Specificity of Self-Efficacy. .......................................................................... 5

Self-efficacy among professionals. ............................................................. 7

Police officer self-efficacy for working with individuals with ASD. .................... 8

Knowledge and Self-Efficacy ................................................................... 9

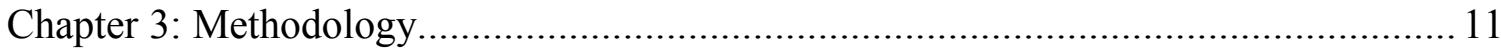

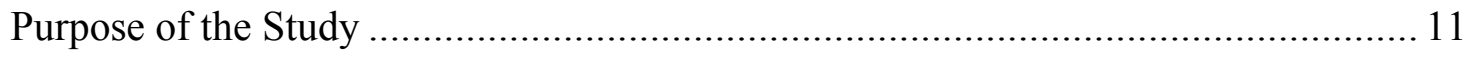

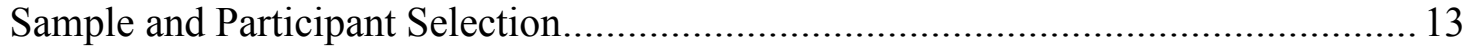

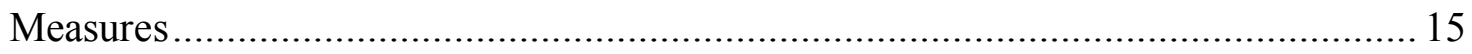

Police officer self-efficacy for working with individuals with ASD. ................... 15

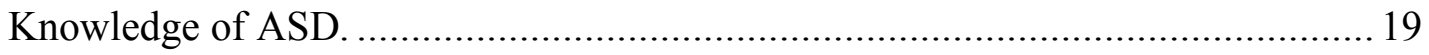

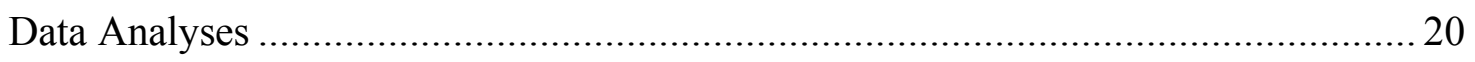

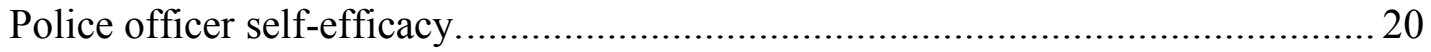

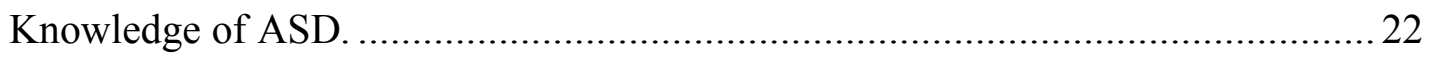

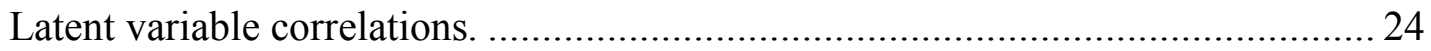

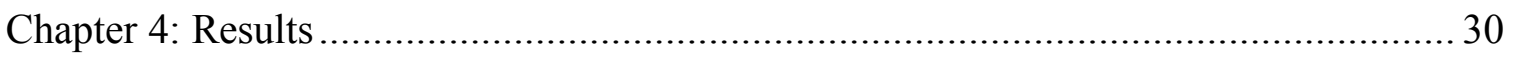

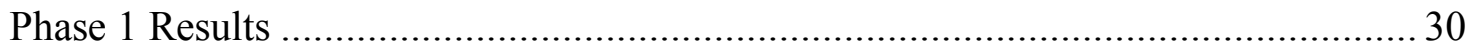

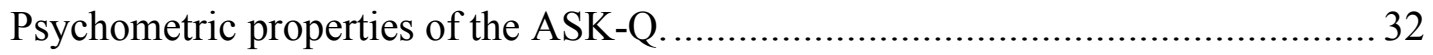

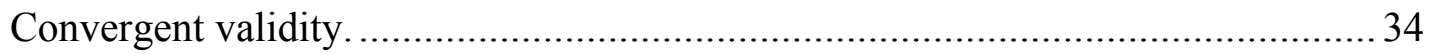


Summary of Scale Modifications Prior to Phase 2

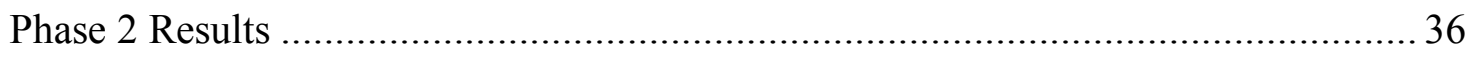

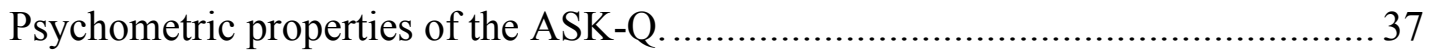

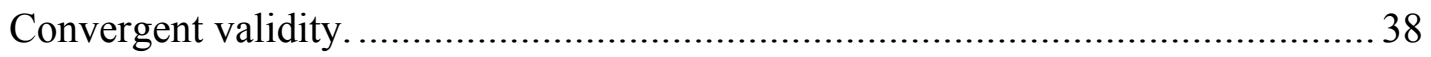

Summary of Scale Modifications After Phase 2 ........................................................ 38

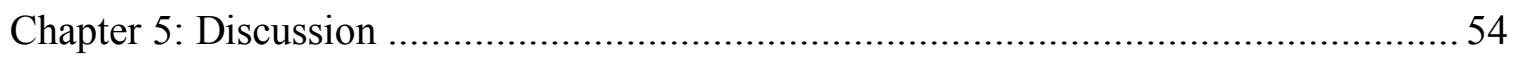

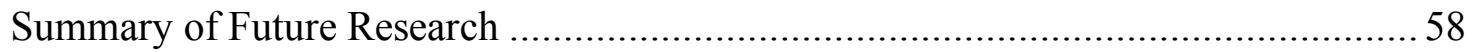

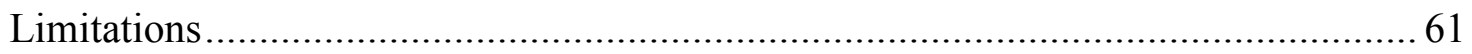

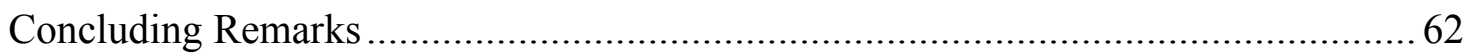

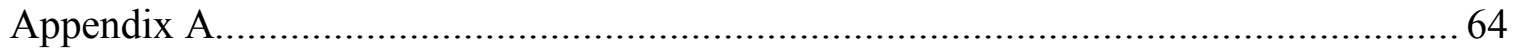

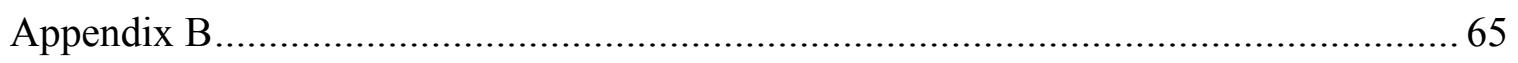

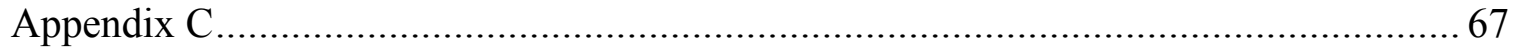

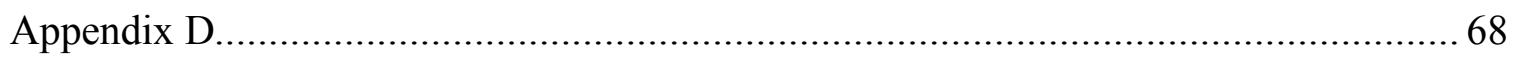

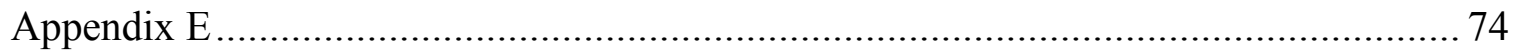

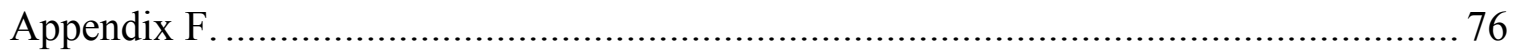

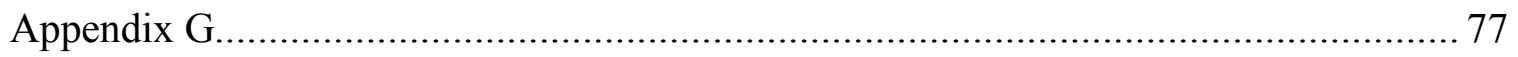

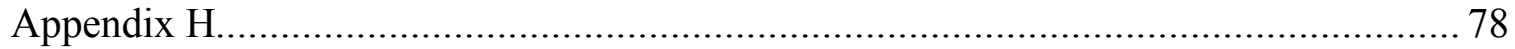

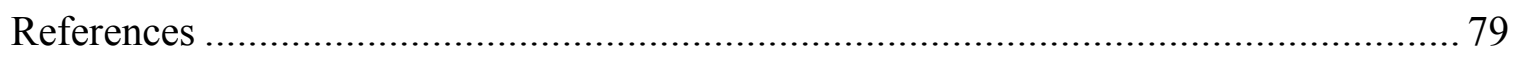

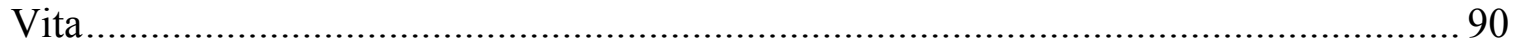




\section{LIST OF TABLES}

Table 1: Description of Study Participants for Phase 1 and Phase 2........................... 26

Table 2: Police Officer Locations Within the United States........................................ 27

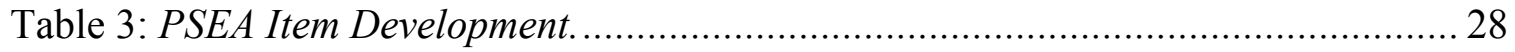

Table 4: Item-Level Descriptive Data for the PSEA Scale Phase $1(\mathrm{~N}=182) \ldots \ldots \ldots \ldots . . . .40$

Table 5: Exploratory Factor Analysis Results for the PSEA Scale in Phase 1 $(\mathrm{N}=182)$ .42

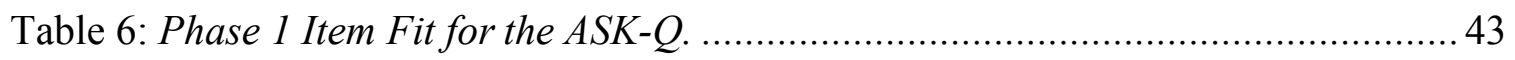

Table 7: Item-Level Descriptive Data for the PSEA Scale Phase $2(\mathrm{~N}=438) \ldots \ldots \ldots \ldots . . . .45$

Table 8: Exploratory Factor Analysis Results for the PSEA Scale in Phase $2(\mathrm{~N}=438) 47$

Table 9: The Police Self-Efficacy for Autism (PSEA) Scale: Phase 2 .......................... 48

Table 10: Fit of Items of the ASK-Q to the Rasch Model in Both Phases ....................... 49 


\section{LIST OF FIGURES}

Figure 1: Steps taken to develop the items for the PSEA scale. ................................. 29

Figure 2: Horn's (1965) parallel analysis completed in Phase 1 on the PSEA items.......51

Figure 3: Phase 1 Wright map from the PSEA scale Rasch analysis.......................... 52

Figure 4: Horn's (1965) parallel analysis completed in Phase 2 on the PSEA items.......53 


\section{Chapter 1: Introduction}

Autism spectrum disorder (ASD) is a complex neurodevelopmental disorder that is characterized by "a range of impairments in social communication and interaction as well as in restricted and repetitive behaviors and interests" (Rice et al., 2016, p. 232). ASD often occurs with other conditions (e.g., intellectual disability) and with common symptoms such as a difficulty to communicate or a tendency to be challenged by social exchanges. Because ASD presents in a diversity of ways, individuals may experience social interactions in a similar way as their neurotypical peers, or they may find social interactions extremely challenging (American Psychiatric Association, 2013). According to a study conducted by the Centers for Disease Control and Prevention (CDC), 1 in 59 children has a diagnosis of ASD, an increase from previous estimates (Baio et al., 2018). The United States responded to the dramatic increase in the prevalence of ASD in 2006 with financial support totaling one billion dollars devoted to research and interventions for this group of individuals (McKeever, 2013). Many communities are supporting individuals with ASD in various ways such as providing "autism-friendly" services (Nagib \& Williams, 2017; Preece, 2003) or ensuring that healthcare workers are educated about ASD (Bakare, Ebigbo, Agomoh, \& Menkiti, 2008).

One important consideration is the role of first responders in providing positive support for individuals with ASD in their communities. According to the United States Bureau of Justice Statistics (2017), the rate of violent victimization against persons with disabilities was 2.5 times higher than the rate for individuals without disabilities (Harrell, 2017). Individuals with disabilities in general are seven times more likely to interact with law enforcement officials than are their neurotypical peers (Debbaudt \& Rothman, 2001; 
Henshaw \& Thomas, 2012; Organization for Autism Research, 2014), and a recent study found that one in five youth with ASD was stopped and questioned by the police before the age of 21 (Rava, Shattuck, Rast, \& Roux, 2017). Furthermore, results from several studies reveal that police officers are often unknowledgeable about ASD and report concerns about how to handle situations appropriately involving persons with ASD, which may lead to problematic interactions between officers and persons with ASD (Chown, 2009; Crane, Maras, Hawken, Mulcahy, \& Memon, 2016).

The core impairments consistent across individuals with ASD (e.g., deficits in communication and social interactions) influence daily functioning and community interactions, and often can be the cause of miscommunication between police officers and persons with ASD. If a police officer misinterprets the behaviors of an individual with ASD or fails to find a way to communicate with a person in crisis, negative outcomes can follow (Copenhaver \& Tewksbury, 2018). Section II of the Americans with Disabilities Act specifies that communities must "take appropriate steps to ensure that communications with applicants, participants, members of the public, and companions with disabilities are as effective as communications with others" (U.S. Department of Justice, 2010, p. 50). Because ASD results in deficits in social communication, police officers need to consider how they will communicate with someone who may not communicate in a traditional manner. Devoting research and support to interventions that target the education of police officers about ASD can help guarantee that their likely interactions within communities are efficient and constructive (Pellicano, Dinsmore, \& Charman, 2014). Knowledgeable officers may even have the opportunity to serve as community resources for families and others navigating the challenges of ASD. 
To better serve communities and as a foundation to their knowledge base, police officers are trained to handle diverse circumstances and individuals. Police officer recruit training has shifted in recent years from a focus on technical and mechanical aspects of policing to a focus on problem solving, diversity training, and community engagement (Chappell, 2007). To be an efficacious officer, one must be willing to serve and protect all individuals and must be able to interact with and support a variety of people within an unpredictable daily environment. This goal, to serve and protect all community members, can be seen in a number of different police department mission statements (e.g., Louisville Metro Police Department, 2019). Many police departments are responding to state mandates that ask for specific training for officers on how to carry out their duties when interacting with someone with ASD (e.g., conducting traffic stops, patrolling designated areas, answering calls for help). As police departments are making more attempts to provide appropriate training to officers, assessment tools must exist to determine the effectiveness of these trainings. For example, scales that measure police officer competencies and beliefs (e.g., knowledge and self-efficacy) specific to working with persons with ASD can help departments evaluate the trainings and understand how to better educate their officers. This study proposes one such measure that will assess police officer self-efficacy to interact with individuals with ASD while serving in their professional role. 


\section{Chapter 2: Theoretical Framework and Literature Review}

To situate this investigation, first I provide an overview of Bandura's (1986) social cognitive theory as the underlying framework. I then discuss how self-efficacy has been studied previously in policing and in similar occupations, including nursing and teaching.

\section{Social Cognitive Theory}

Skinner (1984) and other behaviorists suggested that human functioning could be explained by environmental conditions, not by personal or cognitive factors. Although this theory has been widely accepted among researchers who focus on special education and ASD research, Bandura (1986) suggested a more complex theory where personal factors play a lead role in influencing behaviors. Bandura's (1986) social cognitive theory posits that individuals' behaviors are not only determined by environmental factors, but also by personal factors. Because of this emphasis on personal factors, this theory will serve as the grounding framework for this study.

According to Bandura's (1986) social cognitive theory, human functioning is explained by the reciprocal interactions of personal, environmental, and behavioral factors. Self-efficacy has been studied within the social cognitive theory framework as a personal factor that influences one's behavior and environment bidirectionally. For example, a person's self-efficacy beliefs might change the way the individual perseveres in difficult situations or the effort given in a challenging situation (Bandura, 1986). Police officer self-efficacy is the focus of this study because of the important role self-efficacy can have on how police officers behave and interact with others in their professional responsibilities. 
Social cognitive theory also posits a view of human functioning in which people have agency and a capacity for self-influence over their lives. Intraindividual factors, like beliefs, play a role in determining how individuals will behave in the diverse circumstances they face (Bandura, 1986). Because people are guided by a belief in their own capabilities to carry out certain actions, efficacy beliefs are powerful predictors of behavior (Bandura, 1997). For example, police officers may know that visual strategies are more effective when communicating with an individual with ASD. However, these visual strategies may be unlikely to be initiated by officers if the officers do not believe in their own capability to use them to communicate effectively.

Self-efficacy has also been shown to influence how much effort one gives to a task, how much time one spends persisting in the face of obstacles, and the amount of stress one experiences (Bandura, 1997). Unless officers believe they can successfully interact with an individual with ASD, they may have little incentive to act or may act inappropriately when experiencing a challenging situation. Understanding officers' selfefficacy could help to predict their behavior and motivation to persevere in a challenging situation, such as supporting an individual with ASD during an emergency situation.

Specificity of Self-Efficacy. Bandura (2006) advised that self-efficacy judgments are domain specific. "A high sense of efficacy in one activity domain is not necessarily accompanied by a high self-efficacy in other realms" (Bandura, 1997, p. 42). In other words, self-efficacy changes when individuals consider various tasks or domains of functioning. This means that self-efficacy measures should assess individuals' judgments about their capabilities in a given domain (e.g., parenting, exercising, writing) rather than individuals' global judgments of self-efficacy. 
The scale in this study contains self-efficacy items that assess tasks in one professional domain (i.e., policing) and pertain to one specific group of individuals (i.e., individuals with ASD). Self-efficacy that is specific to police officers working with individuals with ASD has not yet been measured, although such scales have been developed in similar professional domains. For example, Ruble, Toland, Birdwhistell, McGrew, and Usher (2013) created the Autism Self-Efficacy Scale for Teachers (ASSET) to assess the self-efficacy of teachers who work with students with ASD. The proposed scale in this study is similarly specific (e.g., beliefs about interacting with persons with ASD). Measuring self-efficacy at the group-specific level is important given that officers might feel differently when considering their capability for working with a certain group of citizens compared to another (Bailey, Barr, \& Bunting, 2001). This follows the same logic of domain specific self-efficacy scales: An individual's capability beliefs may change depending on the subskills and varying demands of activities. The justification for group-specific self-efficacy is also similar to the examination of personspecific self-efficacy, which has been measured in the field of education where teachers consider student characteristics and report on their self-efficacy for teaching specific students (Zee, Koomen, Jellesma, Geerlings, \& de Jong, 2016). When examining teacher self-efficacy specific to working with students with ASD, Love, Toland, Usher, Campbell, and Spriggs (2019) found the construct to be distinct from, although related to, general teacher self-efficacy. This supports the justification for a self-efficacy scale that is not only specific to a professional domain, but also to professional interactions with a group of individuals. Similar to teaching students with ASD, working with an individual with ASD as a police officer necessitates a unique set of skills and knowledge. Creating a 
scale to measure this construct will help researchers gain an accurate self-report of an officer's capability judgments for working with this group of citizens. Without this level of specificity, construct underrepresentation, or the creation of an instrument that does not fully capture important aspects of the construct, could occur (AERA, APA, \& NCME, 2014).

Self-efficacy among professionals. Although self-efficacy for working with individuals with ASD has not been measured in the profession of policing, self-efficacy has been explored in a number of service and care professions. For example, in nursing, high levels of self-efficacy have been shown to play a protective role against workplace incivility and burnout (Fida, Laschinger, \& Leiter, 2018). Nurses who reported higher self-efficacy also reported lower levels of burnout than their peers. In education, teachers' self-efficacy, or judgments about their capabilities to help their students learn, has been shown to influence a range of outcomes including teachers' stress, psychological wellbeing, and instructional approach (Love, Findley, Ruble, \& McGrew, 2019; Zee \& Koomen, 2016). Teachers who reported higher levels of self-efficacy demonstrated higher quality instruction (Schwarzer \& Hallum, 2008). Higher levels of teaching selfefficacy have also been associated with improved student achievement and motivation (Love et al., 2019; Zee \& Koomen, 2016). Ruble and colleagues (2013) found that teachers who reported higher levels of self-efficacy for working with students with ASD also reported lower levels of stress. It is unclear whether these powerful associations found in professions such as nursing and teaching generalize to police officer occupational tasks; however, developing a psychometrically sound scale that measures self-efficacy in the policing context is a crucial first step. 


\section{Police officer self-efficacy for working with individuals with ASD. The}

associations between police officer self-efficacy for working with individuals with ASD and other outcomes (e.g., stress, job satisfaction, behavior) have not yet been established. Although ASD-specific scales do not exist, police officer self-efficacy has been studied with regard to working with individuals with psychiatric syndromes such as depression or schizophrenia (Bahora, Hanafi, Chien, \& Compton, 2008). Preliminary evidence has pointed to possible outcomes related to police self-efficacy. For example, Bahora and colleagues (2008) created a measure to assess officers' self-efficacy after crisis intervention training. Police officers responded to vignettes about individuals with psychiatric syndromes by answering 10 items and responding using a 4-point Likert-type response format ranging from 1 (Not at All Confident) to 4 (Very Confident). The items, which refer to the vignette, ask officers questions such as, "How confident would you feel interacting with someone like [John]?" The authors created the measure in response to a lack of existing or validated scales designed to assess this specific type of selfefficacy. Results from the study indicated that officer self-efficacy for working with individuals with psychiatric illnesses (e.g., schizophrenia and depression) as well as officer self-efficacy for working with individuals with substance abuse disorders (e.g., cocaine dependency and alcohol dependency) increased after receiving a targeted training.

Researchers using the same scale found that police officer self-efficacy for working with individuals with mental illnesses was significantly and positively associated with better de-escalation skills and referral decisions (Broussard et al., 2011). Although these studies provided an initial examination of police officer capability beliefs, neither 
described how the self-efficacy scale was developed nor how evidence of validity was gathered; therefore, the results should be interpreted with caution (DeVellis, 2012). Validity studies investigating the measure's psychometric characteristics should be conducted to ensure that relevant evidence and rationale exist and are appropriate for the samples the instrument is being used on (AERA, APA, \& NCME, 2014). Furthermore, these limitations in initial police self-efficacy research point to the need for a measure that assesses police self-efficacy for working with individuals with ASD.

\section{Knowledge and Self-Efficacy}

According to social cognitive theory, increasing one's knowledge about a subject also influences one's capacity for personal agency over one's life. In addition to examining police self-efficacy, this study also focuses on officers' knowledge of ASD. Inaccurate or a lack of knowledge of ASD among health care providers has a direct impact on individuals' access to diagnosis and treatment services and on ethnic and racial disparities in service delivery (Harrison et al., 2017; Magaña, Lopez, Aguinaga, \& Morton, 2013). A deficit in the knowledge of ASD for community professionals, including law enforcement officers, was identified as a significant area of research (Gardner, Campbell, \& Westdal, 2018; Harrison, Bradshaw, Naqvi, Paff, \& Campbell, 2017; Harrison, Slane, Hoang, \& Campbell, 2016). Substantial knowledge of ASD can help to decrease the misinterpretations that can occur when an officer is unaware of this diagnosis. Officers with limited knowledge of defining ASD characteristics and strategies to support individuals with ASD could misinterpret the behaviors of an individual with ASD as threatening, related to drugs or alcohol, or as mental illness.

Self-efficacy and knowledge are explored together in this study because, 
according to social cognitive theory, "it is not enough for individuals to possess the requisite knowledge and skills to perform a task; they also must have the conviction that they can successfully perform the required behavior(s) under typical and, importantly, under challenging circumstances" (Artino, 2012, p. 77). Knowledge alone, therefore, is often insufficient. People must believe that they have the skills needed to turn their knowledge into practice under a variety of circumstances (Bandura, 1997). Knowledge and self-efficacy are therefore often studied as joint predictors of behavior (Corona, Christodulu, \& Rinaldi, 2017). More knowledge allows a person to predict events and exercise more control over them (Bandura, 1997). When officers have a firm knowledge of ASD, they may feel better equipped to exercise control over that task. Because an officer who reports knowledge of ASD should feel more competent working with an individual with ASD, it is expected that police officer ASD-specific self-efficacy will be positively associated with officer knowledge of ASD. Highly efficacious police officers who are also knowledgeable of ASD may have the skills to proactively anticipate and plan for a variety of circumstances that they might encounter on the job.

Researchers have previously developed studies that use the relationship between self-efficacy and knowledge to explore how the two constructs can predict behavior. For example, in the context of teaching, Lauermann and König (2016) studied teachers' professional competence by looking at general pedagogical knowledge, teacher selfefficacy, and their relationship to the experiences and behaviors related to teacher burnout (e.g., detachment from colleagues or less personal accomplishment). Teacher self-efficacy and general pedagogical knowledge were positively associated. Teachers who reported more pedagogical knowledge and higher teacher self-efficacy also reported 
fewer experiences that related to burnout. Similar findings have emerged in the context of medicine. For example, Rimal (2000) found that the relationship between diet knowledge and behavior was mediated by diet self-efficacy. He reported that "individuals' ability to act in knowledge-consistent ways is largely a function of their perceived abilities" (Rimal, 2000, p. 230). Police officers who demonstrate higher levels of ASD knowledge and who report higher perceived capabilities to work with individuals with ASD might exhibit more favorable behaviors when working with individuals with ASD. A measure of knowledge is included in this study to test the relationship between ASD knowledge and police self-efficacy for working with individuals with ASD.

\section{Chapter 3: Methodology}

\section{Purpose of the Study}

The purpose of this study was to develop a scale to assess police officer selfefficacy for working with individuals with ASD in accordance with the principles of Bandura's (1986) social cognitive theory and provide initial validity evidence for the interpretation of the scale's score. The newly crafted scale will allow researchers to understand more about police officers' beliefs about working with individuals with ASD. Specifically, I sought to provide initial empirical evidence to support the internal structure of the new scale (and thus its scoring) that was driven by Bandura's (1986) social cognitive theory and evidence based on test content. To support the ongoing research surrounding knowledge of ASD, this study will also provide additional psychometric evidence for the knowledge scale, ensuring validity evidence exists for the sample of police officers that will complete the questionnaire. Finally, this study will provide empirical evidence that scores on the police officers' self-efficacy scale correlate 
with scores on the officers' knowledge of ASD questionnaire as expected based on social cognitive theory and previous literature examining knowledge and self-efficacy in other contexts.

Three primary research questions guided this study:

1. What is the internal structure of items designed to assess police officer self-efficacy for working with individuals with ASD?

2. Do items designed to assess police officer knowledge of ASD reflect a unidimensional structure?

3. Does a moderate and positive significant correlation exist between police officer self-efficacy for working with individuals with ASD and knowledge of ASD?

This study took part in two phases, each involving two separate samples of police officers. In Phase 1, the hypothesis was tested to confirm that the items designed to measure police officer self-efficacy for working with individuals with ASD and items designed to measure officer knowledge of ASD both reflected a unidimensional factor structure. The association between the scores on two measures (i.e., a knowledge of ASD measure and a police officer self-efficacy for working with individuals with ASD measure) was confirmed to be as expected, based on the hypothesis.

Evidence from Phase 1 was used to modify the self-efficacy scale. In Phase 2, responses from a second sample of police officers were collected to further evaluate the psychometric properties of both scales and to examine their relationship. Analysis of the association between police officer self-efficacy for working with individuals with ASD and their knowledge of ASD provided an important source of validity evidence for the 
newly designed scale (AERA, APA, \& NCME, 2014). I hypothesized that the two constructs would be moderately and positively correlated, indicating that officers who reported higher levels of knowledge of ASD would also report higher self-efficacy for working with individuals with ASD. Likewise, officers who do not know much about ASD were hypothesized to report lower levels of self-efficacy for working with individuals with ASD.

\section{Sample and Participant Selection}

Participant recruitment was conducted separately for each phase of this study. The primary purpose of the two-phase data collection effort was to provide an opportunity for iterative refinement of items (see Figure 1). The cumulative scale development process involved item writing and expert review to gather evidence based on test content and response processes and two phases of data collection to gather empirical evidence based on internal structure and relations to other variables.

Active police officers (those who were currently working as law enforcement officers) throughout the United States were considered eligible to participate in this study. Prior to data collection, approval was obtained from the University's Institutional Review Board. Participants were recruited by contacting the Chief of Police at departments across the country. Police forces range in size depending on the population of the county they serve. Larger departments (with at least 400 officers) were targeted for this study to achieve a higher sample size. Once the Chief's permission was provided, a list of all active police officers within the consenting department was secured. Then, an e-mail with a link to an anonymous electronic Qualtrics survey was sent to all officers. During Phase 1 of data collection, reminder emails were sent to each consenting 
department on a weekly basis for two months. During Phase 2 of data collection, the survey remained open for four months, as an extension was required for one participating department who needed to seek approval from their legal department.

In Phase 1, I invited 10 departments (approximately 1,039 police officers) to participate. Two hundred five responses were recorded of which $182(18 \%)$ were deemed usable. Participants who did not consent or did not answer more than one self-efficacy item were deleted $(n=23)$. In Phase 2, I invited 14 departments to participate (approximately 6,840 police officers) and 478 responses were collected of which 438 (7\%) were deemed usable. Participants who did not answer more than one self-efficacy item, who did not give consent, or who reported having a role other than police officer (e.g., police clerk) were deleted $(n=40)$. In total, 620 police officers took part in this study.

Demographic information was gathered electronically at the end of the survey (see Appendix B). In Study 1, police officers were 76\% male, with a mean age of 39 years $(S D=10.27)$. Police officers reported an average of 14 years of law enforcement experience $(S D=8.74)$. Twenty-five percent of police officers reported knowing at least one person with ASD. In Study 2, police officers were 73\% male, with a mean age of 42 years $(S D=8.82)$. Police officers reported an average of 17 years of law enforcement experience $(S D=8.98)$. Approximately $24 \%$ of officers reported knowing at least one person with ASD. Table 1 provides more information on the participants in both phases. Because demographic items were optional, demographic data are missing for some participants. The names of the specific police departments that the officers worked for were not collected to keep the survey anonymous and confidential. However, to estimate 
the spread of participants across the United States, the IP address that officers used to answer the survey was analyzed from Qualtrics data. This information indicated that officers from 19 of the 50 United States took part in this study (see Table 2).

\section{Measures}

Police officer self-efficacy for working with individuals with ASD. The Police Self-Efficacy for Autism (PSEA) scale was developed for this study. Items assessing police officer self-efficacy for working with individuals with ASD were selected through an iterative process including examination of relevant literature, consultation with experts $(n=28)$, cognitive interviews with police officers $(n=3)$, and repetitive item writing (DeVellis, 2012; Kline, 1986; Thorndike \& Thorndike-Christ, 2010). The initial pool of items was developed from informal discussions with police officers, families, individuals with ASD, and from personal experience working with individuals with ASD (see Table 3). Using information from discussions with police officers, I wrote items that reflected a variety of circumstances in which police officers might interact with an individual with ASD. The cognitive interviews and expert review stages further helped to identify which types of tasks would be more or less difficult for a police officer, ensuring the items reflected a range of tasks and difficulties. For example, "I can establish rapport with someone who has autism" was identified as an easier task for police officers because establishing rapport with all individuals is an expected job duty regardless of who the officer is working with. However, officers felt the task of discriminating ASD from other diagnoses (e.g., "I can tell the difference between someone who has autism and someone who is demonstrating drug-induced behavior") would be a more difficult item to answer for officers, depending on an officer's familiarity with ASD. Using input from 
discussions with families and individuals with ASD, I wrote items that reflect challenges police officers might face when interacting with someone with ASD. Communication (e.g., "I can adapt my own verbal language to support someone with ASD with limited communication skills.") and identification (e.g., "I can identify a person with ASD when I see them in the community.") were two aspects of interaction with people with ASD that were focal in the item-writing process. When developing the original pool of items, I also referred to similar self-efficacy scales (e.g., Bahora et al., 2008) to confirm that I was representing the construct fully and to minimize construct underrepresentation.

I mapped the process of item development from the initial pool to the final scale, recording details of when items were added, removed, and changed. Items were revised throughout this process to confirm that they were clear, concise, and distinct. Attention was also given to the extent that items maximized individual differences (DeVellis, 2012). Scale development procedures require a thorough process whereby evidence for validity is gathered from multiple sources to evaluate the appropriateness of a scale for a particular use (AERA, APA, \& NCME, 2014). To accomplish the task of creating items based on a clear process and strong evidence, I reviewed the potential items with 31 individuals in four primary steps of item development (see Figure 1).

Expert review. The first step of item review was consultation with experts. Rubio, Berg-Weger, Tebb, Lee, and Rauch (2003) recommended identifying experts as individuals who share similar demographics as future participants or as individuals who are specialists in the field, with at least three participants per group. Three classes of experts were identified including police officers, family members of persons with ASD, and self-efficacy experts (see Figure 1). Police officers $(n=9)$ qualified as experts if they 
were currently veteran officers who had an experience with a person with ASD while working as a police officer. I gathered experts who were family members of those with ASD $(n=12)$. Finally, self-efficacy experts $(n=7)$ were professors who specialized in the measurement or evaluation of self-efficacy as a construct or professors whose primary area of expertise focused on psychometrics and scale development.

Experts were asked to evaluate three aspects of each item: the clarity of the item wording, the level of item importance, and the degree to which the item was realistic when considering the duties of the police officers. Each expert completed a review of the initial pool of items independently in an iterative process throughout item development (see Figure 1). All experts responded using a 4-point Likert-type response format ranging from 1 (Strongly Disagree) to 4 (Strongly Agree) and had the opportunity to provide further explanation using an open-text box (see Appendix C for a sample expert review item). To determine which items to modify, delete, or retain, I averaged experts' responses to each item. The averages ranged from 1 to 4 , where 1 signified a problematic item, and 4 signified an acceptable item. If the average response was 3.5 or lower, I flagged the item and considered modifying, deleting, or rewording it. Any item that was modified or rewritten was subjected to a subsequent round of expert of review. See Appendix D for details on item modification. I repeated the process of gathering expert review data in multiple rounds until consensus was achieved. Consensus was determined when no experts requested further deletion or modification of the items. In total, there were three rounds of expert reviews.

After the initial round of expert reviews, I conducted a follow-up focus group with three police officers to gather more detailed information on item wording and 
appropriateness for police officers. I asked three police officers to expand on their review of each item and to provide suggested revisions when the item was not clear. This stage was crucial in preparing a set of items that reflected the needs of police officers and included appropriate terminology.

Cognitive interviews. A second step taken in the scale development process involved conducting cognitive interviews with police officers to confirm that they were interpreting the items as intended. The goal of this scale development step was to provide a degree of evidence for validity based on response processes. Evidence based on response processes is a source of evidence that demonstrates the equivalency between the construct being measured and the responses provided by the study participants (AERA, APA, \& NCME, 2014). This step helps "identify items where there is a misalignment between participant interpretation and the developer's intentions and to identify ways to modify those items" (Peterson, Peterson, \& Powell, 2017, p. 217).

Cognitive interview participants $(n=3)$ were recruited through a convenience sample of police officers. The interviews were completed after the second round of expert reviews (see Figure 1). Respondents were selected from one police department who selfreported a range of experiences working with individuals with ASD and a range of experience on the police force (Willis, 1999). To recruit these individuals, a higherranking officer was approached and asked to solicit volunteers. Then, those individuals were contacted to introduce them to this study and understand more about their experience with ASD. When choosing participants, individuals were targeted who had training or experience with ASD as well as those individuals who did not have training or experience with ASD. The purpose of seeking participation from officers with a range of 
experience was to confirm that participants had varying perspectives and levels of knowledge of ASD (Peterson et al., 2017).

During individual cognitive interviews over the phone with each officer, I followed verbal scripts and scripted probes. As the interviewer, I read each item to the officer and asked the officer to "think aloud" and explain what he or she was thinking (Beatty \& Willis, 2007; Willis, 1999). All interviews were reviewed and opportunities for item modification were flagged. At the end of the three cognitive interviews, the items were subjected to one more expert review process. After all rounds of expert reviews and the round of cognitive interviewing, 15 items remained and were passed on to the quantitative data analysis stage where the survey would be administered to officers on a larger scale. Items were given in a random order online to ensure that an item-ordering effect did not occur. In the first phase, participants responded using a 4-point Likert-type response format ranging from 1 (Strongly Disagree) to 4 (Strongly Agree). In the second phase, participants responded using a 4-point Likert-type response format ranging from 1 (I cannot do that) to 4 (I can do that). The details of this change are discussed in the results section between Phase 1 and Phase 2 .

Knowledge of ASD. The Autism Stigma \& Knowledge Questionnaire (ASK-Q) was used to gather a self-assessment of participants' knowledge about ASD (Harrison et al., 2017). The 48-item scale consists of four subscales: (a) diagnosis (18 items), (b) etiology (18 items), (c) treatment (15 items), and (d) stigma (11 items), although the original authors of the questionnaire reported both subscale scores and a total score. The complete scale is included in Appendix E. Participants were asked to "agree" or "disagree" with given statements (e.g., "Vaccinations cause autism."). Items were then 
marked as correct or incorrect according to a scoring guide provided by Harrison et al. (2017). The first item, "I have knowledge of autism," was used as a screener question and was not included in analyses. The authors used diagnostic classification modeling to gather evidence for the initial psychometric properties of the questionnaire including factor structure and item validity. A total score reliability of $\alpha=.88$ was reported by Harrison and colleagues for the 48 items in their scale, which were administered to a sample of 617 participants, comprising of university students $(n=313)$ and members of the general public $(n=304)$.

\section{Data Analyses}

The primary analyses for both phases of this study were aimed at exploring the psychometric properties of the newly developed self-efficacy scale. In addition, psychometric evidence was gathered for the knowledge questionnaire, due to the unique context of the study and the limited availability of psychometric evidence for this scale with a sample of police officers. Categorical data analyses were used throughout this study.

Police officer self-efficacy. First, I investigated item-level descriptive data including means, standard deviations, and frequency distributions. I checked the data for univariate outliers. I evaluated each item by examining a polychoric correlation matrix to ensure that all items are intercorrelated above .30 (DeVellis, 2012; Henson \& Roberts, 2006; see Appendix F). Then, exploratory factor analysis (EFA) was performed using Mplus 8.0 (Muthén \& Muthén, 1999-2018) to explore the psychometric properties of the items that make up the PSEA scale in Phase 1. Substantial changes were made to the items after Phase 1. Therefore, EFA was used to examine self-efficacy items used in 
Phase 2 to ensure that "the results obtained were not a one-time chance occurrence" (DeVellis, 2012, p. 156). The estimator, weighted least squares with mean and variance adjusted (WLMSV), was used because of the ordered response options on the selfefficacy scale (Kline, 2016). I first screened the data to check that the items were suitable for factor analysis by computing the Kaiser-Meyer-Olkin (KMO) measure of sampling adequacy and Bartlett's test of sphericity, based on Pearson correlations. The KMO assesses whether or not items from the sample are adequate for being grouped into factors and ranges from 0 to 1 , with a value of .50 considered borderline and minimally suitable for factor analysis (Costello \& Osborne, 2005; Tabachnick \& Fidell, 2007). Bartlett's test of sphericity should be significant $(p<.05)$ for the items to be considered suitable for EFA. The test provides adequate support for the appropriateness of conducting a factor analysis of the data (Williams, Brown, \& Onsman, 2012).

I used Horn's (1965) parallel analysis $(\mathrm{k}=1000)$ based on Pearson correlations and an examination of the eigenvalues to determine how many factors to extract. This method randomly simulated a data set so that eigenvalues from this study's sample could be compared to artificially simulated eigenvalues (Cokluk \& Kocak, 2016). The number of factors to extract was determined by the eigenvalue in the simulated sample that was higher than that of the actual eigenvalue associated with this study (Cokluk \& Kocak, 2016). Once a solution was determined, items with factor loadings greater than .40 were described as loading on the determined factor (Hair, Black, Babin, Anderson, \& Tatham, 1998; Stevens, 1992). The appropriateness of the factor was based on the results of the analyses, as well as a review of theory and literature (Williams et al., 2012). Finally, to evaluate the internal consistency of items within the scale designed to assess police 
officer self-efficacy for working with individuals with ASD, coefficient omega was calculated ( $\omega$; McDonald, 1999).

Knowledge of ASD. The second research question explored the initial psychometric properties of the ASK-Q when used within a sample of police officers. Rasch analysis was used to assess the psychometric properties of the items on the questionnaire and to refine the measure according to how the data fit the model (Bond \& Fox, 2015). Rasch techniques allowed for a superior examination of the instrument once unidimensionality was established, including multiple reliability scores, item difficulty values, and person ability scores (Bond \& Fox, 2015; Boone, 2016). Finally, Rasch was specifically chosen because it allowed for an in depth examination of the dichotomous ASK-Q items as well as additional item-level fit information that is not gathered from traditional factor analysis techniques. Rasch analysis was performed using WINSTEPS version 3.70 (Linacre, 2016).

One specific area of analysis was in the scale's dimensionality. Harris and colleagues (2017) reported four subscales (i.e., diagnosis, etiology, treatment, stigma) as well as a total score reliability. I hypothesized that police officers, who are not experts in ASD, would respond to all of the ASK-Q items consistently. That is, police officers who demonstrate more accurate knowledge of ASD diagnosis by answering those items correctly and consistently would demonstrate similar consistency to the other three subscales and the associated items. Therefore, I hypothesized that a total score could be calculated for the items on the ASK-Q for this sample of police officers. Because of this hypothesis, the dimensionality assessment began with an a priori unidimensional model representing “Autism Knowledge.” Modeled variance and unexplained variance were 
examined to confirm that modeled variance was over $50 \%$ and that unexplained variance was minimal. Then, a Rasch Principal Components Analysis (R-PCA) of the item residuals was conducted to examine the contrasts (correlated residual clusters that would point to multidimensional data; Linacre, 2019).

Finally, to evaluate the reliability of the ASK-Q, internal consistency (i.e., $\alpha$ ), personal separation reliability, and item separation reliability were examined. Person separation reliability provides a value to represent how well participants can be differentiated on the construct of interest. Item separation reliability is similar, but provides an estimate of the spread of items across the construct of interest (Bond \& Fox, 2015). The suggested cutoff for person and item separation reliability is a value greater than .70 (Linacre, 2019).

Next, item fit was assessed to indicate how well data conformed to the unidimensional model (Bond \& Fox, 2015). Infit statistics were calculated as the weighted average of squared residuals, and outfit statistics were calculated as the unweighted average of squared residuals (Bond \& Fox, 2015). In Rasch analyses, a mean-squares (MNSQ) and standardized $Z$ statistic (ZSTD) are offered for all infit and outfit statistics. For the purposes of this study, infit statistics were the primary tool for determining misfit. Outfit values were not examined, as they are influenced by outliers (Linacre, 2019). However, for this data, outliers were expected because many participants could have inconsistent responses to the ASK-Q items depending on their degree of knowledge and experience with persons with ASD. Therefore, infit values were determined to be the most appropriate tool to use when flagging misfitting items. 
Ideal fit ranges change depending on the importance of the test instrument, item, and respondent characteristics. For the purposes of this analysis, items displaying an infit MnSq between 0.70 to 1.30 and infit ZSTD between -2.0 to 2.0 were considered acceptable (Bond \& Fox, 2015; Linacre, 2019). Item misfit could suggest that an item is not contributing to the measurement of the construct and therefore should be flagged for further examination. Items that were flagged as misfitting items (e.g., items that contained an infit value out of the expected range) in Phase 1 were carefully assessed in Phase 2. If an item demonstrated an infit value outside of the expected range in both phases, it would be removed for the correlation analyses, to determine the impact the item had on the overall instrument. The correlation analysis would therefore serve as a sensitivity analysis, allowing for conservative removal of the item. If the conclusions made from the correlation analyses were consistent for both the original ASK-Q and the shortened ASK-Q, the item would be retained but flagged for future studies. Finally, if an item demonstrated an infit value outside of the expected range in only Phase 2, it would be retained.

Latent variable correlations. To answer Research Question 3, latent variable correlations were used to assess the strength of association between scores from the police officer self-efficacy measure and scores assessing police officer knowledge of ASD. These analyses were conducted in both phases of this study. The final conclusions were based on results from Phase 2 after both scales had been refined. The correlations were used to test the hypothesis that scores from the police officer self-efficacy measure were significantly and positively related to scores assessing police officer knowledge of ASD scale. 
If any changes were made to the scale in Phase 1 and 2, latent variable correlations would be run on the full 48-item ASK-Q and a modified version of the ASKQ (excluding any items that were flagged during measurement refinement). The purpose of completing the correlation analyses on both versions of the ASK-Q was to determine if the versions provided similar conclusions. This serves as evidence for, or against, the shortened version of the ASK-Q for future studies. 

Table 1

Description of Study Participants for Phase 1 and Phase 2

\begin{tabular}{|c|c|c|}
\hline & $\begin{array}{c}\text { Phase 1 } \\
(N=182)\end{array}$ & $\begin{array}{c}\text { Phase 2 } \\
(N=438)\end{array}$ \\
\hline Police Officer Characteristics & Frequency $(\%)$ & Frequency $(\%)$ \\
\hline \multicolumn{3}{|l|}{ Gender } \\
\hline Male & $138(75.8)$ & $318(72.6)$ \\
\hline Female & $22(13.7)$ & $83(18.9)$ \\
\hline Other & $1 \quad(0.5)$ & $2 \quad(0.5)$ \\
\hline Missing & $21(10.0)$ & $(8.0)$ \\
\hline \multicolumn{3}{|l|}{ Education } \\
\hline High School Diploma & $21(11.5)$ & $58(13.2)$ \\
\hline GED (High School Equivalency Certificate) & $1 \quad(0.5)$ & $4 \quad(0.9)$ \\
\hline Associate's Degree & $28(15.4)$ & $65(14.8)$ \\
\hline Bachelor's Degree & $18 \quad(9.9)$ & $70(16.0)$ \\
\hline Master's Degree & $85(46.7)$ & $181(41.3)$ \\
\hline Doctoral Degree $(\mathrm{PhD})$ & $1 \quad(0.5)$ & $3(0.7)$ \\
\hline Other & $5 \quad(2.7)$ & $(4.3)$ \\
\hline Missing & $23(12.8)$ & $(8.7)$ \\
\hline \multicolumn{3}{|l|}{ Ethnicity/Race } \\
\hline White & $143(78.6)$ & $326(74.4)$ \\
\hline Latino or Hispanic & $2(1.1)$ & $30 \quad(6.8)$ \\
\hline American Indian or Alaska Native & $0 \quad(0.0)$ & $(0.0)$ \\
\hline Asian or Asian American & $2(1.1)$ & $(1.8)$ \\
\hline Native Hawaiian or Pacific Islander & $0 \quad(0.0)$ & $(0.0)$ \\
\hline Black or African American & $11(6.0)$ & $(5.9)$ \\
\hline Two or More Races & $3(1.6)$ & $(1.6)$ \\
\hline Other & $1(0.5)$ & (1.4) \\
\hline Missing & $20(11.0)$ & $(6.8)$ \\
\hline \multicolumn{3}{|l|}{ Personal Connection To Autism } \\
\hline "I know one person with autism" & $45(24.7)$ & $103(23.5)$ \\
\hline "I know two people with autism" & $24(13.2)$ & $69(15.8)$ \\
\hline "I know three or more people with autism" & $41(22.5)$ & $138(31.5)$ \\
\hline $\begin{array}{l}\text { "No, I am not aware of anyone in my own personal } \\
\text { life" }\end{array}$ & $52(28.6)$ & $93(21.2)$ \\
\hline Missing & $20(11.0)$ & $(8.0)$ \\
\hline \multicolumn{3}{|l|}{ Professional Experience With Autism } \\
\hline "Never" & $7 \quad(3.8)$ & $23 \quad(5.3)$ \\
\hline "Once a year" & $52(28.6)$ & $150(34.2)$ \\
\hline "Once a month" & $48(26.4)$ & $90(20.5)$ \\
\hline “Once a week" & $6 \quad(3.3)$ & $32 \quad(7.3)$ \\
\hline “Once a day” & $7 \quad(3.8)$ & $13(3.0)$ \\
\hline "I'm not sure" & $42(23.1)$ & $95 \quad(21.7)$ \\
\hline Missing & $20(11.0)$ & $35 \quad(8.0)$ \\
\hline
\end{tabular}


Table 2

Police Officer Locations Within the United States

\begin{tabular}{lr} 
State & $n$ \\
\hline Alabama & 1 \\
California & 2 \\
Colorado & 2 \\
Florida & 7 \\
Georgia & 126 \\
Illinois & 13 \\
Indiana & 17 \\
Kentucky & 160 \\
Missouri & 5 \\
Mississippi & 19 \\
North Carolina & 19 \\
Ohio & 83 \\
Oklahoma & 15 \\
South Carolina & 30 \\
Tennessee & 7 \\
Texas & 99 \\
Virginia & 4 \\
Wisconsin & 1 \\
West Virginia & 4 \\
State unknown & 6 \\
\hline Note. Partipant
\end{tabular}

Note. Participant location was gathered from the IP address from which participants took the online survey. 

Table

PSEA Item Development

\begin{tabular}{|c|c|c|}
\hline & Item & Source \\
\hline & \multicolumn{2}{|l|}{ When working as a police officer... } \\
\hline 1 & $\begin{array}{l}\text {...I can use an alternative communication } \\
\text { strategy when speaking with someone } \\
\text { with ASD who has limited verbal } \\
\text { communication. }\end{array}$ & Conversations with police \\
\hline 2 & $\begin{array}{l}\text {...I can deescalate a situation with an } \\
\text { individual with ASD who is harming } \\
\text { their caregiver. }\end{array}$ & Conversations with police \\
\hline 3 & $\begin{array}{l}\text {...I can identify a person with ASD when I } \\
\text { see them in the community. }\end{array}$ & Conversations with police \\
\hline 4 & $\begin{array}{l}\text {...I can calm down a person with ASD who } \\
\text { is having a behavioral meltdown. }\end{array}$ & $\begin{array}{l}\text { Conversations with police and parents } \\
\text { of individuals with ASD }\end{array}$ \\
\hline 5 & ...I can interact with someone with ASD. & Conversations with police \\
\hline 6 & $\begin{array}{l}\text {...I can tell another officer how to identify } \\
\text { if someone has ASD. }\end{array}$ & $\begin{array}{l}\text { Experience teaching and working with } \\
\text { individuals with ASD }\end{array}$ \\
\hline 7 & ...I can talk to someone who has ASD. & Conversations with police \\
\hline 8 & $\begin{array}{l}\text {...I can distinguish ASD from other } \\
\text { disabilities. }\end{array}$ & Conversations with police \\
\hline 9 & $\begin{array}{l}\text {..I can recognize when a person is } \\
\text { "stimming." }\end{array}$ & $\begin{array}{l}\text { Conversations with parents of } \\
\text { individuals with ASD }\end{array}$ \\
\hline 10 & $\begin{array}{l}\text {...I can distinguish ASD from someone } \\
\text { who is using drugs. }\end{array}$ & Conversations with police \\
\hline 11 & $\begin{array}{l}\text {... can recognize limited eye contact as a } \\
\text { characteristic of someone with ASD. }\end{array}$ & $\begin{array}{l}\text { Conversations with individuals with } \\
\text { ASD }\end{array}$ \\
\hline 12 & $\begin{array}{l}\text {...I can adapt my own verbal language to } \\
\text { support someone with ASD with limited } \\
\text { communication skills. }\end{array}$ & $\begin{array}{l}\text { Conversations with parents of } \\
\text { individuals with ASD }\end{array}$ \\
\hline 13 & $\begin{array}{l}\text {...I can support a parent with a child with } \\
\text { ASD who is having a behavioral } \\
\text { meltdown. }\end{array}$ & $\begin{array}{l}\text { Experience teaching and working with } \\
\text { individuals with ASD }\end{array}$ \\
\hline 14 & $\begin{array}{l}\text {...I can use an individual's special interest } \\
\text { to connect with someone with ASD. }\end{array}$ & $\begin{array}{l}\text { Experience teaching and working with } \\
\text { individuals with ASD }\end{array}$ \\
\hline 15 & $\begin{array}{l}\text {...I can ask appropriate questions targeted } \\
\text { to the characteristics of individuals with } \\
\text { ASD when I am supporting a child who } \\
\text { has eloped. }\end{array}$ & $\begin{array}{l}\text { Experience teaching and working with } \\
\text { individuals with ASD }\end{array}$ \\
\hline 16 & $\begin{array}{l}\text {...I can seek appropriate information from a } \\
\text { caregiver when trying to learn more } \\
\text { about someone with ASD. }\end{array}$ & $\begin{array}{l}\text { Conversations with parents of } \\
\text { individuals with ASD }\end{array}$ \\
\hline
\end{tabular}




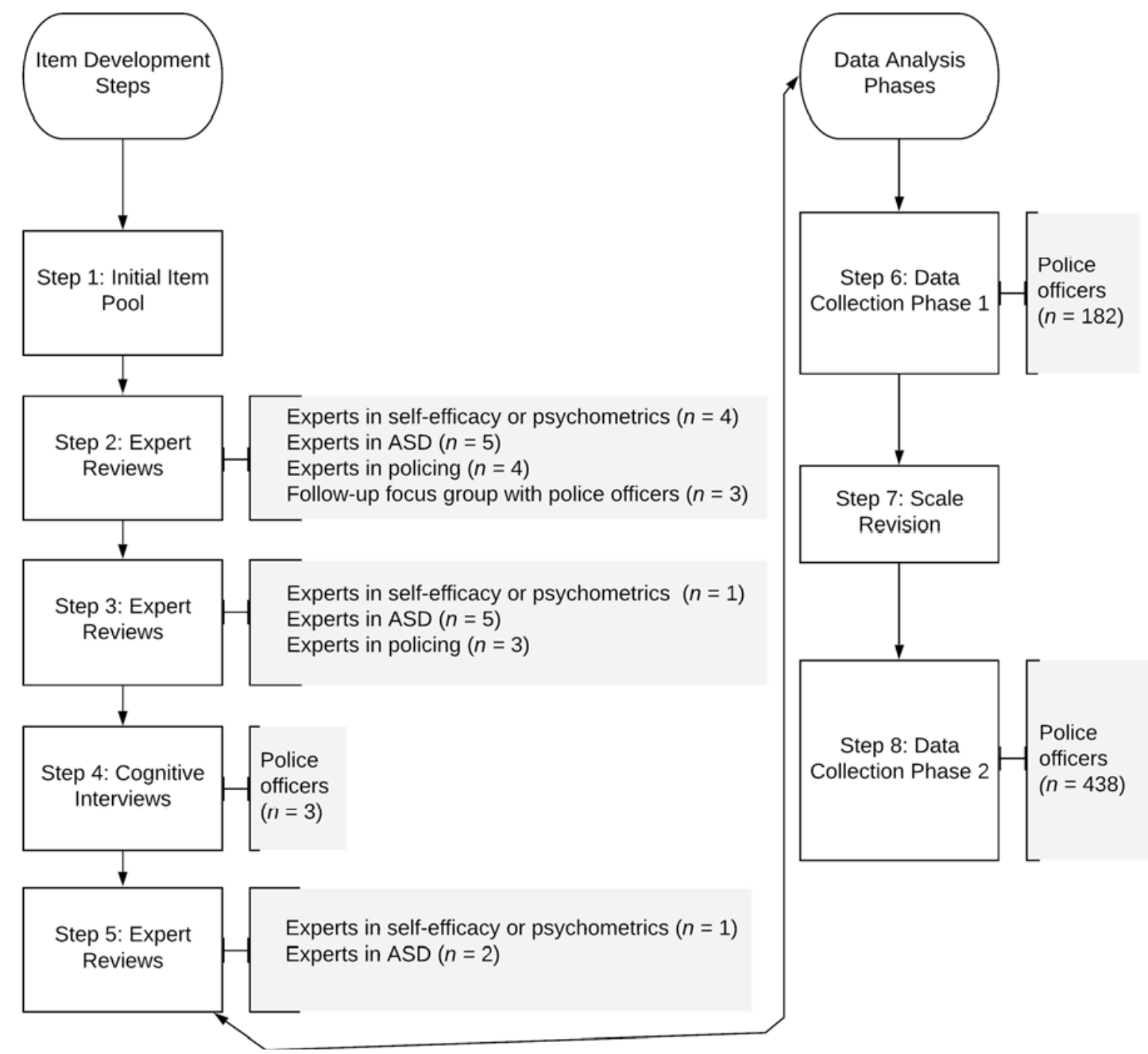

Figure 1. Steps taken to develop the Police Self-Efficacy for Autism (PSEA) scale. This process includes two phases of data collection. Steps were taken to confirm that this study reflected multiple sources of validity and reliability evidence. 


\section{Chapter 4: Results}

\section{Phase 1 Results}

Phase 1 involved the careful creation and revision of items to assess police officer self-efficacy. This process was based on expert reviews and cognitive interviewing. Fifteen items emerged and were then shared with 182 officers through an online survey. The goal of Phase 1 was to explore the psychometric properties of 15 items on the newly developed scale and to test the hypothesis that a unidimensional solution exists. Results of the item-level descriptive data including means, standard deviations, skewness, and kurtosis are presented in Table 4. No violations were discovered within the data and all items fell within an acceptable range of skewness and kurtosis (see Table 4). The items were further evaluated by examining a polychoric correlation matrix to ensure that all items were intercorrelated above .30 (see Appendix F). Based on this matrix, only Item 13 ("I can look for an ID when I cannot get personal information verbally from an individual with autism") was flagged for possible removal or modification because it demonstrated consistently low correlations $(<.30)$ with other items.

To continue the review of the descriptive data, frequency distributions of each item were examined to understand how officers used each of the response format categories (see Table 4). Categories 3 ("Somewhat Agree") and 4 ("Strongly Agree") were used the most, and Categories 1 ("Strongly Disagree”) and 2 ("Somewhat Disagree") were used less frequently. Item 13 ("I can look for an ID when I cannot get personal information verbally from an individual with ASD") and Item 14 ("I can inform a concerned citizen about autism") were the most discriminating items, and Item 1 ("I can identify some signs of autism when I observe them") and Item 12 ("I can seek 
appropriate information from a caregiver when trying to learn more about someone with autism") were the least discriminating items.

Next, an EFA was conducted to examine the internal structure of the items designed to assess police officer self-efficacy. The Kaiser-Meyer-Olkin measure of sampling was .88, which is above the recommended value of .50 (Williams et al., 2012). Bartlett's test of sphericity was statistically significant $(941.34, p<.001)$. A scree procedure (Cattell, 1966) and Horn's (1965) parallel analysis were conducted, and the results revealed that a unidimensional solution represented the 15 PSEA items for this sample (see Figure 2). Factor pattern loadings are presented in Table 5. All items loaded heavily $(\lambda \geq .50)$ on Factor 1 , except for Item $13(\lambda=.28)$. Internal consistency reliability was based on coefficient omega, $\omega=.88$ bootstrap corrected [BC] $95 \%$ CI $[.83, .91]$. Coefficient omega was calculated using ML.

Item 13 ("I can look for an ID when I cannot get personal information verbally from an individual with autism") was flagged during the item-level descriptive stage and again during the EFA. Because the item represents an important behavior for police officers to carry out with individuals with ASD (i.e., obtaining identifying information when a person is not communicating verbally) and because empirical evidence showed that the item was one of the most discriminating, it was not deleted. Instead, the item wording was modified (i.e., "I can gather identifying information from someone with autism who does not use verbal speech."). This modification was written in consultation with two individuals including a police officer and a family member of an individual with ASD. Both individuals advocated for inclusion of the item. 
Item 6 ("I can recognize which of the behaviors below are frequently associated with autism") and Item 7 ("I can correctly identify which of the following are common in people with autism") were also reviewed, as the format of these two items varied from that of the other items. Although empirical data did not suggest that these items were problematic, further review was sought given the uniqueness of the format. A team of psychometric experts was consulted to review the item wording and format. For these two items, officers were asked to judge their capability to respond to a set of behaviors often associated with autism. Review with the team revealed that the items were not written in a clear and singular way, and could be confusing to officers. In addition, some suggested that the items seemed to assess ASD knowledge instead of self-efficacy to work with someone with ASD. The items were originally included in the scale in an attempt to represent a difficult tasks for police officers. However, before moving to the second phase, I needed to confirm that each item was clear and appropriate and that officers would understand the items in the same way that they understood items with alternate formatting (e.g., those that did not list behaviors). The psychometric consultants determined that these items were too different in format and therefore could present unnecessary challenges to respondents. They were therefore removed, which resulted in a 13-item PSEA scale for Phase 2.

Psychometric properties of the ASK-Q. A secondary goal of this study was to evaluate the psychometric properties (e.g., dimensionality, item difficulty) of items designed to assess knowledge of ASD (i.e., the ASK-Q) among a sample of police officers. The results of the analyses are described below. 
Dimensionality assessment. Outcomes of the R-PCA were used to confirm unidimensionality. Results indicated that $45.8 \%$ of the variance was explained by the ASK-Q model. The contrasts (correlated residual clusters) were further investigated to ensure that a unidimensional structure with uncorrelated random residuals was present (Linacre, 2019). Results indicated that the existing contrasts represented less than $4 \%$ of the unexplained variance. These results provided confirming evidence for the unidimensional structure of the data. Calculating a total score for items is therefore appropriate for presenting officers' knowledge of ASD, which henceforth is referred to as "ASD Knowledge."

Reliability. Rasch methods were used to evaluate the reliability of the ASK-Q. Person separation reliability for the questionnaire was satisfactory at .83. Item separation reliability was also found to be acceptable at .97 . Finally, the overall internal consistency was very good $(\alpha=.91)$.

Measurement refinement. After unidimensionality was established, the ASK-Q was further examined to confirm that all items contributed to the construct (knowledge of ASD). Infit values were examined according to recommendations by Bond and Fox (2015) to determine whether items needed to be flagged for removal prior to Phase 2 analyses. Five items were flagged for further review (see Table 6). Item 3 ("Children with autism may have strange reactions to the way things smell, taste, look, feel, or sound"; $\mathrm{MnSq}=0.6, \mathrm{ZSTD}=-1.5$ ), Item 26 ("Some children with autism show intense interest in parts of objects"; $\mathrm{MnSq}=0.7, \mathrm{ZSTD}=-1.4$ ), Item 29 ("Autism is a communication disorder"; $\mathrm{MnSq}=1.2, \mathrm{ZSTD}=3.2$ ), Item 48 ("Many children with autism get upset if their routine is changed"; $\mathrm{MnSq}=0.6, \mathrm{ZSTD}=-1.4$ ), and Item 49 ("Autism is due to 
cold, rejecting parents"; $\mathrm{MnSq}=0.5, \mathrm{ZSTD}=-1.7$ ) showed misfit (i.e., scores were outside of the expected range) and were flagged. These items were not deleted, but flagged for further review in Phase 2.

Item difficulty. A variable map of the ASK-Q items was examined (see Figure 3), which detailed the item and participant locations for the 182 police officers who completed the ASK-Q. Specifically, this map was explored to determine whether the items represented an appropriate range of easy to difficult items. Figure 3 shows the items on the ASK-Q according to their order of difficulty, with the easier items at the bottom and the more difficult items at the top. Overall, the results indicated an acceptable range of item difficulty. The difficulties of the items were compared to the abilities of the participants. Evidence showed that more items were easier to endorse (or to answer correctly) than were difficult to endorse. For example, Item 20, "Children with autism do not enjoy the presence of others," was relatively more difficult to answer correctly. For the ASK-Q, "difficult to endorse" indicates that an item would require more of the latent trait (e.g., autism knowledge) to answer correctly. That is, police officers who demonstrated more ASD knowledge would be more likely be able to answer a difficult item correctly, whereas police officers who demonstrated less ASD knowledge would be less likely to answer that item correctly. For example, Item 48, "Many children with autism get upset if their routine is changed," was easy to endorse.

Convergent validity. Research Question 3 explored the association between the two primary variables in this study. For this analysis, the two variables (e.g., PSEA and ASD knowledge) were treated as latent variables and the correlations were therefore latent variable correlations between the measurement models that represent each 
construct. Results indicated that there was a significant and positive relationship between scores from the knowledge scale and scores from the self-efficacy scale $(r=.35,95 \% \mathrm{CI}$ $[.33, .38])$

\section{Summary of Scale Modifications Prior to Phase 2}

Three major modifications were made to the PSEA scale prior to data collection in Phase 2. First, two items were removed. This decision reflected the iterative process of scale development and was based on a review with a team of experts who identified possible problematic wording. Second, Item 13 was modified as a result of empirical evidence (i.e., weak factor loading) and further consultation with experts.

Finally, the response format was changed before Phase 2 data collection. This modification was supported by a review of the response categories used and by consultation with a team of experts from a university psychometric research lab. The team reviewed the response format and contemplated modification options that might help to discriminate among participants. A change in response format was proposed because the majority of the officers answered in Categories 3 ("Somewhat Agree") and 4 ("Strongly Agree"). The difference between the two middle categories (Somewhat Agree \& Somewhat Disagree) may have also been difficult to discern. Further, asking officers to "agree" to an item that describes a behavior may be more confusing than directly asking for a judgment of their own capabilities.

After reflecting on these possibilities and conversing with experts, it was determined that the scale would benefit from a response format that was more closely tied to self-efficacy theory. Bandura (2006) called for a response format that permits participants to judge their own efficacy with "intermediate degrees of assurance" (p. 
312). The response format was changed for Phase 2 as follows: 1 ("I cannot do that"), 2 ("I doubt I can do that"), 3 ("I'm fairly certain I can do that"), and 4 ("I can do that"). This modified response format was reviewed with experts in policing to verify that officers would find the format easy to understand. I hypothesized that the change in response format may provide additional item-level variability, as officers would more clearly understand how to answer the items. Because this was a major change to the selfefficacy scale, a second exploratory factor analysis was necessary to examine how officers were responding to the new items and response format.

No changes were made to the ASK-Q in Phase 1. An identical copy of the ASK-Q was used in Phase 2; however, four items were flagged for further review in Phase 2 (i.e., Items 3, 26, 48, and 49). These items were flagged based on empirical evidence (e.g., Infit values) and a review of the item wording.

\section{Phase 2 Results}

The aim of the second phase of this study was to evaluate further the psychometric properties of the Police Self-efficacy for Autism (PSEA) scale with a new sample of 438 police officers. Because there were substantial changes between the first iteration and the second (i.e., change in response format, item deletion, and additional items), an EFA was appropriate for examining the structure of the data. I first reviewed item-level descriptive data including means, standard deviations, and frequency distributions for the 13 items used in Phase 2 (see Table 7). No univariate outliers were identified, the skewness and kurtosis values were acceptable, and the polychoric correlation matrix showed that all items were intercorrelated above .30 (see Appendix G). 
In Phase 2, when police officers answered the items on the PSEA scale, they responded to a 4-point Likert-type response format as follows: 1 (I cannot do that), 2 (I doubt I can do that), 3 (I'm fairly certain I can do that), and 4 (I can do that). I hypothesized that reducing the ambiguity in response format might provide additional item-level variability, as officers would better understand how to answer the items. However, an examination of the frequency distributions of each item revealed that Category 3 and 4 were still used most often (see Table 7). Item 10 ("I can seek appropriate information from a caregiver when trying to learn more about someone with autism") was the least discriminating item and Item 11 ("I can gather identifying information from someone with autism who does not use verbal speech") was one of the most discriminating items.

Next, I conducted an EFA to explore the internal structure of the PSEA scale. Preliminary statistics were first gathered to determine the appropriateness of the EFA. The Kaiser-Meyer-Olkin measure of sampling was .905 , which is above the recommended value of .50 (Williams et al., 2012). Bartlett's test of sphericity was statistically significant (2052.51, $p<.001)$. Results of Horn's (1965) parallel analysis revealed that a unidimensional solution represented the 13-item PSEA scale (see Figure 4). Factor pattern loadings are presented in Table 8 . All items loaded heavily $(\lambda \geq .50)$ on the single factor. Internal consistency for the 13 items was $\omega=.89$ bootstrap corrected [BC] 95\% CI [.86, .91]. The results from Phase 2 were reviewed together, and all 13 items were retained for final version of the PSEA scale (see Table 9).

Psychometric properties of the ASK-Q. A secondary goal of Phase 2 was to replicate the analyses completed on the ASK-Q in Phase 1. The 48-item ASK-Q was 
presented to participants in Phase 2. Results of the R-PCA in Phase 2 indicated that $48.0 \%$ of the variance was explained by the ASK-Q model. An examination of contrasts revealed that the unexplained variance less than $3 \%$ for all contrasts. These results were similar to the dimensionality findings in Phase 1.

Measurement refinement. Results of the Phase 2 Rasch analyses showed that one of the original five misfitting items, Item 29, continued to demonstrate misfit ("Autism is a communication disorder"). Table 10 shows the fit statistics for both phases. Because this item demonstrated misfit in both phases, a 47-item version of the ASK-Q (without Item 29) and a 48-item version of the ASK-Q (with Item 29 included) would be examined in the correlation analyses to determine the impact Item 29 had on the overall instrument.

Reliability. Person separation reliability for the questionnaire was consistently satisfactory at .83 . Item separation reliability was also found to be acceptable at .99 . Finally, the overall internal consistency was good $(\alpha=.92)$.

Convergent validity. A final analytic step in this study involved using latent variable correlations to evaluate the association between police officer self-efficacy for working with individuals with ASD and police officer knowledge of ASD. These findings were replicated in the second phase $(r=.46,95 \%$ CI $[.42, .49])$ and did not change when the 47-item ASK-Q was used.

\section{Summary of Scale Modifications After Phase 2}

Following Phase 2, no further changes were made to the PSEA scale. One item (e.g., Item 29) on the ASK-Q was flagged based on a combination of results from both phases. A decision was made to retain this item because a sensitivity analysis revealed no 
differences between the 47-item ASK-Q and the 48-item ASK-Q. 
Table 4

Item-Level Descriptive Data for the PSEA Scale Phase $1(\mathrm{~N}=182)$

\begin{tabular}{|c|c|c|c|c|c|c|c|c|c|}
\hline \multirow[b]{2}{*}{ Item } & \multirow[b]{2}{*}{ Item phrasing } & \multirow[b]{2}{*}{$M$} & \multirow[b]{2}{*}{$S D$} & \multirow[b]{2}{*}{ Skew. } & \multirow[b]{2}{*}{ Kurt. } & \multicolumn{4}{|c|}{$\begin{array}{l}\text { Response Frequency } \\
\qquad(\%)\end{array}$} \\
\hline & & & & & & $\begin{array}{l}\text { Strongly } \\
\text { Disagree }\end{array}$ & $\begin{array}{l}\text { Somewhat } \\
\text { Disagree }\end{array}$ & $\begin{array}{l}\text { Somewhat } \\
\text { Agree }\end{array}$ & $\begin{array}{l}\text { Strongly } \\
\text { Agree }\end{array}$ \\
\hline PSEA1 & $\begin{array}{l}\text { I can identify some signs of autism when I } \\
\text { observe them. }\end{array}$ & 3.28 & 0.58 & -0.49 & 1.56 & $\begin{array}{c}2 \\
(1.0)\end{array}$ & $\begin{array}{c}5 \\
(2.4)\end{array}$ & $\begin{array}{c}231 \\
(52.7)\end{array}$ & $\begin{array}{c}173 \\
(39.5)\end{array}$ \\
\hline PSEA2 & $\begin{array}{l}\text { I can de-escalate a situation in which a } \\
\text { person with autism is harming others. }\end{array}$ & 2.96 & 0.64 & -0.66 & 1.56 & $\begin{array}{c}5 \\
(2.4)\end{array}$ & $\begin{array}{c}23 \\
(11.2)\end{array}$ & $\begin{array}{c}285 \\
(65.1)\end{array}$ & $\begin{array}{c}100 \\
(22.8)\end{array}$ \\
\hline PSEA3 & $\begin{array}{l}\text { I can de-escalate a situation in which a } \\
\text { person with autism is harming himself or } \\
\text { herself. }\end{array}$ & 3.07 & 0.62 & -0.51 & 1.42 & $\begin{array}{c}3 \\
(1.5)\end{array}$ & $\begin{array}{c}17 \\
(8.3)\end{array}$ & $\begin{array}{l}278 \\
(63.5)\end{array}$ & $\begin{array}{l}106 \\
(24.2)\end{array}$ \\
\hline PSEA4 & $\begin{array}{l}\text { I can explain at least three general } \\
\text { characteristics of a person with autism to } \\
\text { another police officer who asks. }\end{array}$ & 3.04 & 0.76 & -0.39 & -0.28 & $\begin{array}{c}4 \\
(2.0)\end{array}$ & $\begin{array}{c}33 \\
(16.1)\end{array}$ & $\begin{array}{c}197 \\
(45.0)\end{array}$ & $\begin{array}{c}155 \\
(35.4)\end{array}$ \\
\hline PSEA5 & $\begin{array}{l}\text { I can distinguish autism from other } \\
\text { disabilities. }\end{array}$ & 2.86 & 0.63 & -0.61 & 1.20 & $\begin{array}{c}5 \\
(2.4)\end{array}$ & $\begin{array}{c}32 \\
(15.6)\end{array}$ & $\begin{array}{c}293 \\
(66.9)\end{array}$ & $\begin{array}{c}65 \\
(14.8)\end{array}$ \\
\hline PSEA6 & $\begin{array}{l}\text { I can recognize which of the behaviors } \\
\text { below are frequently associated with } \\
\text { autism: }\end{array}$ & 3.08 & 0.71 & -0.52 & 0.37 & $\begin{array}{c}4 \\
(2.0)\end{array}$ & $\begin{array}{c}24 \\
(11.7)\end{array}$ & $\begin{array}{c}246 \\
(56.2)\end{array}$ & $\begin{array}{c}142 \\
(32.4)\end{array}$ \\
\hline PSEA7 & $\begin{array}{l}\text { I can correctly identify which of the } \\
\text { following are common in people with } \\
\text { autism: }\end{array}$ & 3.15 & 0.63 & -0.56 & 1.37 & $\begin{array}{c}3 \\
(1.5)\end{array}$ & $\begin{array}{c}13 \\
(6.3)\end{array}$ & $\begin{array}{c}227 \\
(51.8)\end{array}$ & $\begin{array}{c}175 \\
(40.0)\end{array}$ \\
\hline PSEA8 & $\begin{array}{l}\text { I can tell the difference between someone } \\
\text { who has autism and someone who is } \\
\text { demonstrating drug-induced behavior. }\end{array}$ & 3.29 & 0.72 & -0.80 & 0.38 & $\begin{array}{c}3 \\
(1.5)\end{array}$ & $\begin{array}{c}17 \\
(8.3)\end{array}$ & $\begin{array}{c}274 \\
(62.6)\end{array}$ & $\begin{array}{c}131 \\
(29.9)\end{array}$ \\
\hline
\end{tabular}


Table 4 (continued)

\begin{tabular}{|c|c|c|c|c|c|c|c|c|c|}
\hline \multirow[b]{2}{*}{ Code } & \multirow[b]{2}{*}{ Item } & \multirow[b]{2}{*}{$M$} & \multirow[b]{2}{*}{$S D$} & \multirow[b]{2}{*}{ Skew. } & \multirow[b]{2}{*}{ Kurt. } & \multicolumn{4}{|c|}{$\begin{array}{c}\text { Response Frequency } \\
(\%)\end{array}$} \\
\hline & & & & & & $\begin{array}{r}\text { Strongly } \\
\text { Disagree }\end{array}$ & $\begin{array}{l}\text { Somewhat } \\
\text { Disagree }\end{array}$ & $\begin{array}{l}\text { Somewhat } \\
\text { Agree }\end{array}$ & $\begin{array}{l}\text { Strongly } \\
\text { Agree }\end{array}$ \\
\hline PSEA9 & $\begin{array}{l}\text { I can adapt the way I communicate to } \\
\text { explain something to a person with autism. }\end{array}$ & 3.21 & 0.68 & -0.63 & 0.63 & $\begin{array}{c}3 \\
(1.5)\end{array}$ & $\begin{array}{c}16 \\
(7.8)\end{array}$ & $\begin{array}{c}237 \\
(54.1)\end{array}$ & $\begin{array}{c}131 \\
(29.0)\end{array}$ \\
\hline PSEA10 & $\begin{array}{l}\text { I can establish rapport with someone who } \\
\text { has autism. }\end{array}$ & 3.09 & 0.58 & -0.01 & -0.05 & $\begin{array}{c}0 \\
(0)\end{array}$ & $\begin{array}{c}21 \\
(10.2)\end{array}$ & $\begin{array}{c}111 \\
(54.1)\end{array}$ & $\begin{array}{c}37 \\
(18.0)\end{array}$ \\
\hline PSEA11 & $\begin{array}{l}\text { I can use what I know about autism to help } \\
\text { find an individual with autism who has } \\
\text { become a missing person. }\end{array}$ & 2.99 & 0.75 & -0.67 & 0.67 & $\begin{array}{c}8 \\
(3.9)\end{array}$ & $\begin{array}{c}24 \\
(11.7)\end{array}$ & $\begin{array}{c}100 \\
(48.8)\end{array}$ & $\begin{array}{c}38 \\
(18.5)\end{array}$ \\
\hline PSEA12 & $\begin{array}{l}\text { I can seek appropriate information from a } \\
\text { caregiver when trying to learn more about } \\
\text { someone with autism. }\end{array}$ & 3.39 & 0.65 & -0.86 & 0.90 & $\begin{array}{c}2 \\
(1.0)\end{array}$ & $\begin{array}{c}9 \\
(4.4)\end{array}$ & $\begin{array}{c}78 \\
(38.0)\end{array}$ & $\begin{array}{c}39 \\
(38.5)\end{array}$ \\
\hline PSEA13 & $\begin{array}{l}\text { I can look for an ID when I cannot get } \\
\text { personal information verbally from an } \\
\text { individual with autism. }\end{array}$ & 2.82 & 0.81 & -0.38 & -0.35 & $\begin{array}{c}11 \\
(5.4)\end{array}$ & $\begin{array}{c}42 \\
(20.5)\end{array}$ & $\begin{array}{c}86 \\
(42.0)\end{array}$ & $\begin{array}{c}33 \\
(16.1)\end{array}$ \\
\hline PSEA14 & $\begin{array}{l}\text { I can inform a concerned citizen about } \\
\text { autism. }\end{array}$ & 2.89 & 0.79 & -0.60 & 0.35 & $\begin{array}{c}11 \\
(5.4)\end{array}$ & $\begin{array}{c}30 \\
(14.6)\end{array}$ & $\begin{array}{c}95 \\
(46.3)\end{array}$ & $\begin{array}{c}33 \\
(16.1)\end{array}$ \\
\hline PSEA15 & $\begin{array}{l}\text { I can modify the environment to help an } \\
\text { individual with autism feel calm during an } \\
\text { emergency. }\end{array}$ & 3.11 & 0.59 & -0.38 & 1.46 & $\begin{array}{c}2 \\
(1.0)\end{array}$ & $\begin{array}{c}15 \\
(7.3)\end{array}$ & $\begin{array}{c}115 \\
(56.1)\end{array}$ & $\begin{array}{c}37 \\
(18.0)\end{array}$ \\
\hline
\end{tabular}

Note. Skew. = skewness; Kurt. $=$ kurtosis 
POLICE SELF-EFFICACY

Table 5

Exploratory Factor Analysis Results for the PSEA Scale in Phase $1(\mathrm{~N}=182)$

\begin{tabular}{lll}
\hline Item & $h^{2}$ & $\lambda$ \\
\hline 1. I can identify some signs of autism when I observe them. & .67 & .82 \\
2. I can de-escalate a situation in which a person with autism is harming & .46 & .68 \\
others. & & \\
3. I can de-escalate a situation in which a person with autism is harming & .53 & .73 \\
$\quad$ himself or herself. & & \\
4. I can explain at least three general characteristics of a person with autism to & .53 & .73 \\
$\quad$ another police officer who asks. & .56 & .75 \\
5. I can distinguish autism from other disabilities. & .53 & .73 \\
6. I can recognize which of the behaviors below are frequently associated &
\end{tabular}

with autism:

- Hearing voices

- Avoidance of eye contact

- Lack of balance

- Repetitive body motions

- Slurred speech

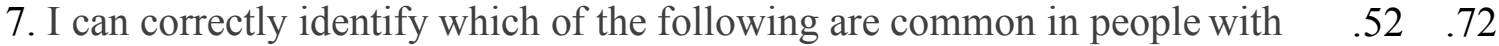
autism:

- Communication challenges

- Mental illness

- Social anxiety

- Physical impairment

- Intellectual disability

8. I can tell the difference between someone who has autism and someone who is demonstrating drug-induced behavior.

9. I can adapt the way I communicate to explain something to a person with $\quad \begin{array}{rl}.52 & .72\end{array}$ autism.

10. I can establish rapport with someone who has autism.

$.25 \quad .50$

11. I can use what I know about autism to help find an individual with autism

$.52 \quad .72$ who has become a missing person.

12. I can seek appropriate information from a caregiver when trying to learn more about someone with autism.

13. I can look for an ID when I cannot get personal information verbally from $\quad .08 \quad .28$ an individual with autism.

14. I can inform a concerned citizen about autism.

15. I can modify the environment to help an individual with autism feel calm during an emergency.

Note. $h^{2}=$ communalities; $\lambda=$ factor loading. $47.95 \%$ of common variance was explained by the factor solution 
POLICE SELF-EFFICACY

Table 6

Phase 1 Item Fit for the ASK-Q

\begin{tabular}{llc}
\hline Items & Infit MnSQ & Infit ZSTD \\
\hline ASKQ_2 & 0.9 & -0.4 \\
ASKQ_3 & $\mathbf{0 . 6}$ & $\mathbf{- 1 . 5}$ \\
ASKQ_4 & 1.1 & 1.1 \\
ASKQ_5 & 0.7 & -1.5 \\
ASKQ_6 & 1.1 & 0.5 \\
ASKQ_7 & 0.9 & -0.2 \\
ASKQ_8 & 1.1 & 1.5 \\
ASKQ_9 & 0.1 & -0.4 \\
ASKQ_10 & 1.2 & 1.1 \\
ASKQ_11 & 0.9 & -0.2 \\
ASKQ_12 & 0.9 & -0.2 \\
ASKQ_13 & 1.0 & 0.0 \\
ASKQ_14 & 0.9 & -0.2 \\
ASKQ_15 & 1.1 & 0.8 \\
ASKQ_16 & 1.1 & 1.0 \\
ASKQ_17 & 1.0 & 0.2 \\
ASKQ_18 & 1.3 & 1.2 \\
ASKQ_19 & 1.0 & 0.2 \\
ASKQ_20 & 1.0 & -0.2 \\
ASKQ_21 & 1.1 & 0.3 \\
ASKQ_22 & 1.1 & 0.9 \\
ASKQ_23 & 1.0 & 0.1 \\
ASKQ_24 & 1.0 & 0.0 \\
ASKQ_25 & 1.1 & 0.8 \\
ASKQ_26 & $\mathbf{0 . 7}$ & $\mathbf{- 1 . 4}$ \\
ASKQ_27 & 1.0 & 0.0 \\
ASKQ_28 & 1.0 & -0.2 \\
ASKQ_29 & $\mathbf{1 . 2}$ & $\mathbf{3 . 2}$ \\
ASKQ_30 & 1.0 & 0.1 \\
ASKQ_31 & 1.1 & 1.5 \\
ASKQ_32 & 0.8 & -1.3 \\
ASKQ_33 & 0.7 & -0.9 \\
ASKQ_34 & 0.9 & -0.5 \\
ASKQ_35 & 1.0 & 0.6 \\
ASKQ_36 & 0.8 & -0.8 \\
ASKQ_37 & 1.0 & -0.1 \\
ASKQ_38 & 1.1 & 0.4 \\
ASKQ_39 & 1.1 & 0.7 \\
ASKQ_40 & 1.0 & 0.3 \\
ASKQ_41 & 1.1 & 0.9 \\
& &
\end{tabular}


POLICE SELF-EFFICACY

Table 6 (continued)

\begin{tabular}{llc}
\hline Items & Infit MnSQ & Infit ZSTD \\
\hline ASKQ_42 & 1.1 & 0.6 \\
ASKQ_43 & 0.7 & -1.2 \\
ASKQ_44 & 1.0 & -0.2 \\
ASKQ_45 & 1.1 & 0.4 \\
ASKQ_46 & 0.9 & -0.5 \\
ASKQ_47 & 1.0 & 0.1 \\
ASKQ_48 & $\mathbf{0 . 6}$ & $\mathbf{- 1 . 4}$ \\
ASKQ_49 & $\mathbf{0 . 5}$ & $\mathbf{- 1 . 7}$ \\
\hline
\end{tabular}

Note. Misfitting items had an infit MnSQ between 0.7 and 1.3 and an infit ZSTD between -2.0 and 2.0. Misfitting values are flagged in bold for further review. 
Table 7

Item-Level Descriptive Data for the PSEA Scale Phase $2(\mathrm{~N}=438)$

\begin{tabular}{|c|c|c|c|c|c|c|c|c|c|}
\hline \multirow[b]{2}{*}{ Code } & \multirow[b]{2}{*}{ Item } & \multirow[b]{2}{*}{$M$} & \multirow[b]{2}{*}{$S D$} & \multirow[b]{2}{*}{ Skew. } & \multirow[b]{2}{*}{ Kurt. } & \multicolumn{4}{|c|}{ Response Frequency $(\%)$} \\
\hline & & & & & & $\begin{array}{l}\text { I cannot } \\
\text { do that }\end{array}$ & $\begin{array}{l}\text { I doubt I } \\
\text { can do that }\end{array}$ & $\begin{array}{l}\text { I'm fairly } \\
\text { certain I } \\
\text { can do } \\
\text { that }\end{array}$ & $\begin{array}{l}\text { I can do } \\
\text { that }\end{array}$ \\
\hline PSEA1 & $\begin{array}{l}\text { I can identify some signs of autism when I } \\
\text { observe them. }\end{array}$ & 3.36 & 0.58 & 0.58 & -0.26 & $\begin{array}{c}1 \\
(0.2)\end{array}$ & $\begin{array}{c}19 \\
(4.3)\end{array}$ & $\begin{array}{c}231 \\
(52.7)\end{array}$ & $\begin{array}{c}173 \\
(39.5)\end{array}$ \\
\hline PSEA2 & $\begin{array}{l}\text { I can de-escalate a situation in which a } \\
\text { person with autism is harming others. }\end{array}$ & 3.14 & 0.56 & 0.56 & 0.02 & 0 & $\begin{array}{c}30 \\
(9.1)\end{array}$ & $\begin{array}{c}285 \\
(65.1)\end{array}$ & $\begin{array}{c}100 \\
(22.8)\end{array}$ \\
\hline PSEA3 & $\begin{array}{l}\text { I can de-escalate a situation in which a } \\
\text { person with autism is harming himself or } \\
\text { herself. }\end{array}$ & 3.16 & 0.57 & 0.57 & 0.27 & $\begin{array}{c}1 \\
(0.2)\end{array}$ & $\begin{array}{c}35 \\
(8.0)\end{array}$ & $\begin{array}{c}278 \\
(63.5)\end{array}$ & $\begin{array}{c}106 \\
(24.2)\end{array}$ \\
\hline PSEA4 & $\begin{array}{l}\text { I can explain at least three general } \\
\text { characteristics of a person with autism to } \\
\text { another police officer who asks. }\end{array}$ & 3.17 & 0.77 & 0.78 & 0.07 & $\begin{array}{c}12 \\
(2.7)\end{array}$ & $\begin{array}{c}59 \\
(13.5)\end{array}$ & $\begin{array}{c}197 \\
(45.0)\end{array}$ & $\begin{array}{c}155 \\
(35.4)\end{array}$ \\
\hline PSEA5 & $\begin{array}{l}\text { I can distinguish autism from other } \\
\text { disabilities. }\end{array}$ & 2.97 & 0.62 & 0.62 & 1.63 & $\begin{array}{c}11 \\
(2.5)\end{array}$ & $\begin{array}{c}54 \\
(12.3)\end{array}$ & $\begin{array}{c}293 \\
(66.9)\end{array}$ & $\begin{array}{c}65 \\
(14.8)\end{array}$ \\
\hline PSEA6 & $\begin{array}{l}\text { I can tell the difference between someone } \\
\text { who has autism and someone who is } \\
\text { demonstrating drug-induced behavior. }\end{array}$ & 3.24 & 0.63 & 0.63 & 0.66 & $\begin{array}{c}5 \\
(1.1)\end{array}$ & $\begin{array}{c}32 \\
(7.3)\end{array}$ & $\begin{array}{c}246 \\
(56.2)\end{array}$ & $\begin{array}{c}142 \\
(32.4)\end{array}$ \\
\hline PSEA7 & $\begin{array}{l}\text { I can adapt the way I communicate to } \\
\text { explain something to a person with autism. }\end{array}$ & 3.36 & 0.59 & 0.59 & -0.27 & $\begin{array}{c}1 \\
(0.2)\end{array}$ & $\begin{array}{c}22 \\
(5.0)\end{array}$ & $\begin{array}{c}227 \\
(51.8)\end{array}$ & $\begin{array}{c}175 \\
(40.0)\end{array}$ \\
\hline PSEA8 & $\begin{array}{l}\text { I can establish rapport with someone who } \\
\text { has autism. }\end{array}$ & 3.26 & 0.54 & 0.54 & 0.11 & $\begin{array}{c}1 \\
(0.2)\end{array}$ & $\begin{array}{l}18 \\
(4.1)\end{array}$ & $\begin{array}{c}274 \\
(62.6)\end{array}$ & $\begin{array}{c}131 \\
(29.9)\end{array}$ \\
\hline PSEA9 & $\begin{array}{l}\text { I can use what I know about autism to help } \\
\text { find an individual with autism who has }\end{array}$ & 3.16 & 0.68 & 0.68 & 0.37 & $\begin{array}{c}7 \\
(1.6)\end{array}$ & $\begin{array}{c}49 \\
(11.2)\end{array}$ & $\begin{array}{c}237 \\
(54.1)\end{array}$ & $\begin{array}{c}131 \\
(29.0)\end{array}$ \\
\hline
\end{tabular}


Table 7 (continued)

\begin{tabular}{|c|c|c|c|c|c|c|c|c|c|}
\hline \multirow[b]{2}{*}{ Code } & \multirow[b]{2}{*}{ Item } & \multirow[b]{2}{*}{$M$} & \multirow[b]{2}{*}{$S D$} & \multirow[b]{2}{*}{ Skew. } & \multirow[b]{2}{*}{ Kurt. } & \multicolumn{4}{|c|}{ Response Frequency $(\%)$} \\
\hline & & & & & & $\begin{array}{l}\text { I cannot } \\
\text { do that }\end{array}$ & $\begin{array}{l}\text { I doubt I } \\
\text { can do that }\end{array}$ & $\begin{array}{l}\text { I'm fairly } \\
\text { certain I } \\
\text { can do } \\
\text { that }\end{array}$ & $\begin{array}{l}\text { I can do } \\
\text { that }\end{array}$ \\
\hline PSEA10 & $\begin{array}{l}\text { I can seek appropriate information from a } \\
\text { caregiver when trying to learn more about } \\
\text { someone with autism. }\end{array}$ & 3.61 & 0.54 & 0.54 & 0.68 & $\begin{array}{c}1 \\
(0.2)\end{array}$ & $\begin{array}{c}9 \\
(2.1)\end{array}$ & $\begin{array}{c}143 \\
(32.6)\end{array}$ & $\begin{array}{c}271 \\
(61.9)\end{array}$ \\
\hline PSEA11 & $\begin{array}{l}\text { I can gather identifying information from } \\
\text { someone with autism who does not use } \\
\text { verbal speech. }\end{array}$ & 2.91 & 0.70 & 0.70 & -0.19 & $\begin{array}{c}8 \\
(1.8)\end{array}$ & $\begin{array}{c}101 \\
(23.1)\end{array}$ & $\begin{array}{c}236 \\
(53.9)\end{array}$ & $\begin{array}{c}79 \\
(18.0)\end{array}$ \\
\hline PSEA12 & $\begin{array}{l}\text { I can inform a concerned citizen about } \\
\text { autism. }\end{array}$ & 3.11 & 0.80 & 0.80 & -0.26 & $\begin{array}{c}13 \\
(3.0)\end{array}$ & $\begin{array}{c}75 \\
(17.1)\end{array}$ & $\begin{array}{c}191 \\
(43.6)\end{array}$ & $\begin{array}{c}146 \\
(33.3)\end{array}$ \\
\hline PSEA13 & $\begin{array}{l}\text { I can modify the environment to help an } \\
\text { individual with autism feel calm during an } \\
\text { emergency. }\end{array}$ & 3.24 & 0.67 & 0.66 & 0.15 & $\begin{array}{c}4 \\
(0.9)\end{array}$ & $\begin{array}{c}41 \\
(9.3)\end{array}$ & $\begin{array}{c}227 \\
(51.8)\end{array}$ & $\begin{array}{c}152 \\
(34.7)\end{array}$ \\
\hline
\end{tabular}

Note. Skew. = skewness; Kurt. = kurtosis 
POLICE SELF-EFFICACY

Table 8

Exploratory Factor Results for the PSEA Scale in Phase $2(\mathrm{~N}=438)$

\begin{tabular}{lll}
\hline Item & $h^{2}$ & $\lambda$ \\
\hline 1. I can identify some signs of autism when I observe them & .71 & .84 \\
2. I can de-escalate a situation in which a person with autism is & .64 & .80 \\
harming others. & & .76 \\
3. I can de-escalate a situation in which a person with autism is & .58 & .76 \\
$\quad$ harming himself or herself. & .50 & .71 \\
4. I can explain at least three general characteristics of a person with & & .40 \\
$\quad$ autism to another police officer who asks. & .63 \\
5. I can distinguish autism from other disabilities. & .29 & .54 \\
6. I can recognize which of the behaviors below are frequently &
\end{tabular}
associated with autism:

- Hearing voices

- Avoidance of eye contact

- Lack of balance

- Repetitive body motions

- Slurred speech

7. I can correctly identify which of the following are common in people with autism:

- Communication challenges

- Mental illness

- Social anxiety

- Physical impairment

- Intellectual disability

8. I can tell the difference between someone who has autism and someone who is demonstrating drug-induced behavior.

9. I can adapt the way I communicate to explain something to a person with autism.

10. I can establish rapport with someone who has autism.

11. I can use what I know about autism to help find an individual with autism who has become a missing person.

$.37 \quad .61$

12. I can seek appropriate information from a caregiver when trying to learn more about someone with autism.

13. I can look for an ID when I cannot get personal information verbally from an individual with autism.

Note. $h^{2}=$ communalties, $\lambda=$ standardized factor loadings, $69.92 \%$ of common variance was explained by the factor solution 
POLICE SELF-EFFICACY

Table 9

The Police Self-Efficacy for Autism (PSEA) Scale: Phase 2

PSEA1 I can identify some signs of autism when I observe them

PSEA2 I can de-escalate a situation in which a person with autism is harming others.

PSEA3 I can de-escalate a situation in which a person with autism is harming himself or herself.

PSEA4 I can explain at least three general characteristics of a person with autism to another police officer who asks.

PSEA5 I can distinguish autism from other disabilities.

PSEA6 I can tell the difference between someone who has autism and someone who is demonstrating drug-induced behavior.

PSEA7 I can adapt the way I communicate to explain something to a person with autism.

PSEA8 I can establish rapport with someone who has autism.

PSEA9 I can use what I know about autism to help find an individual with autism who has become a missing person.

PSEA10 I can seek appropriate information from a caregiver when trying to learn more about someone with autism.

PSEA11 I can gather identifying information from someone with autism who does not use verbal speech.

PSEA12 I can inform a concerned citizen about autism.

PSEA13 I can modify the environment to help an individual with autism feel calm during an emergency.

Note. Respondents replied using a 4-point Likert-type response format that ranged from 1 (I cannot do that) to 4 (I can do that). The stem for each item was "When working as a police officer." See Appendix H for the actual scale used during data collection. 
POLICE SELF-EFFICACY

Table 10

Fit of Items of the ASK-Q to the Rasch Model in Both Phases

\begin{tabular}{|c|c|c|c|c|}
\hline \multirow[b]{2}{*}{ Items } & \multicolumn{2}{|c|}{$\begin{array}{c}\text { Phase 1 } \\
(N=182) \\
\end{array}$} & \multicolumn{2}{|c|}{$\begin{array}{l}\text { Phase } 2 \\
(N=438)\end{array}$} \\
\hline & Infit MnSQ & Infit ZSTD & Infit MnSQ & Infit ZSTD \\
\hline ASKQ_2 & 0.9 & -0.4 & 1.1 & 0.9 \\
\hline ASKQ_3 & 0.6 & -1.5 & 0.9 & 0.0 \\
\hline ASKQ_4 & 1.1 & 1.1 & 0.1 & -0.4 \\
\hline ASKQ_5 & 0.7 & -1.5 & 0.9 & -0.5 \\
\hline ASKQ_6 & 1.1 & 0.5 & 0.9 & -0.9 \\
\hline ASKQ_7 & 0.9 & -0.2 & 0.8 & -1.1 \\
\hline ASKQ_8 & 1.1 & 1.5 & 1.1 & 1.5 \\
\hline ASKQ 9 & 0.9 & -0.4 & 1.1 & 0.3 \\
\hline ASKQ_10 & 1.2 & 1.1 & 1.0 & 0.0 \\
\hline ASKQ_11 & 0.9 & -0.2 & 0.9 & 0.0 \\
\hline ASKQ_12 & 0.9 & -0.2 & 0.9 & -0.1 \\
\hline ASKQ_13 & 1.0 & 0.0 & 1.1 & 1.0 \\
\hline ASKQ_14 & 0.9 & -0.2 & 1.0 & -0.1 \\
\hline ASKQ 15 & 1.1 & 0.8 & 1.0 & 0.3 \\
\hline ASKQ_16 & 1.1 & 1.0 & 1.1 & 0.8 \\
\hline ASKQ_17 & 1.0 & 0.2 & 0.8 & -1.1 \\
\hline ASKQ_18 & 1.3 & 1.2 & 0.9 & -0.7 \\
\hline ASKQ_19 & 1.0 & 0.2 & 0.9 & -0.8 \\
\hline ASKQ_20 & 1.0 & -0.2 & 1.1 & 0.9 \\
\hline ASKQ_21 & 1.1 & 0.3 & 1.0 & 0.2 \\
\hline ASKQ_22 & 1.1 & 0.9 & 1.0 & 0.5 \\
\hline ASKQ_23 & 1.0 & 0.1 & 0.9 & -0.5 \\
\hline ASKQ_24 & 1.0 & 0.0 & 1.0 & -0.2 \\
\hline ASKQ_25 & 1.1 & 0.8 & 1.1 & 1.5 \\
\hline ASKQ_26 & 0.7 & -1.4 & 0.7 & -1.2 \\
\hline ASKQ_27 & 1.0 & 0.0 & 0.7 & -1.1 \\
\hline ASKQ_28 & 1.0 & -0.2 & 1.0 & -0.6 \\
\hline ASKQ_29 & 1.2 & 3.2 & 1.2 & 5.0 \\
\hline ASKQ_30 & 1.0 & 0.1 & 1.1 & 0.4 \\
\hline ASKQ_31 & 1.1 & 1.5 & 1.1 & 1.7 \\
\hline ASKQ_32 & 0.8 & -1.3 & 1.0 & 0.1 \\
\hline ASKQ_33 & 0.7 & -0.9 & 0.8 & -1.1 \\
\hline ASKQ_34 & 0.9 & -0.5 & 1.0 & 0.3 \\
\hline ASKQ_35 & 1.0 & 0.6 & 1.1 & 2.1 \\
\hline ASKQ_36 & 0.8 & -0.8 & 0.8 & -0.6 \\
\hline ASKQ_37 & 1.0 & -0.1 & 0.8 & -1.1 \\
\hline ASKQ_38 & 1.1 & 0.4 & 1.0 & 0.3 \\
\hline ASKQ_39 & 1.1 & 0.7 & 1.1 & 0.6 \\
\hline ASKQ 40 & 1.0 & 0.3 & 1.1 & 1.7 \\
\hline
\end{tabular}


POLICE SELF-EFFICACY

Table 10 (continued)

\begin{tabular}{llclc}
\hline & \multicolumn{2}{c}{$\begin{array}{c}\text { Phase 1 } \\
(N=182)\end{array}$} & \multicolumn{2}{c}{$\begin{array}{c}\text { Phase 2 } \\
(N=438)\end{array}$} \\
\hline Items & Infit MnSQ & Infit ZSTD & Infit MnSQ & Infit ZSTD \\
\hline ASKQ_41 & 1.1 & 0.9 & 1.0 & 0.2 \\
ASKQ_42 & 1.1 & 0.6 & 1.0 & 0.0 \\
ASKQ_43 & 0.7 & -1.2 & 0.9 & -0.5 \\
ASKQ_44 & 1.0 & -0.2 & 1.0 & 0.3 \\
ASKQ_45 & 1.1 & 0.4 & 1.0 & -0.1 \\
ASKQ_46 & 0.9 & -0.5 & 1.1 & 0.6 \\
ASKQ_47 & 1.0 & 0.1 & 1.0 & -0.1 \\
ASKQ_48 & $\mathbf{0 . 6}$ & $\mathbf{- 1 . 4}$ & 0.9 & -0.6 \\
ASKQ_49 & $\mathbf{0 . 5}$ & $\mathbf{- 1 . 7}$ & 0.9 & -0.7 \\
\hline
\end{tabular}

Note. Item misfit was determined according to whether the infit MnSQ was between 0.70 and 1.30 (inclusion in the range indicated fit), and whether the infit ZSTD was between 2.0 and 2.0 (inclusion in the range indicated fit). Misfitting values (those outside of the range) from both phases are flagged in bold. 
POLICE SELF-EFFICACY

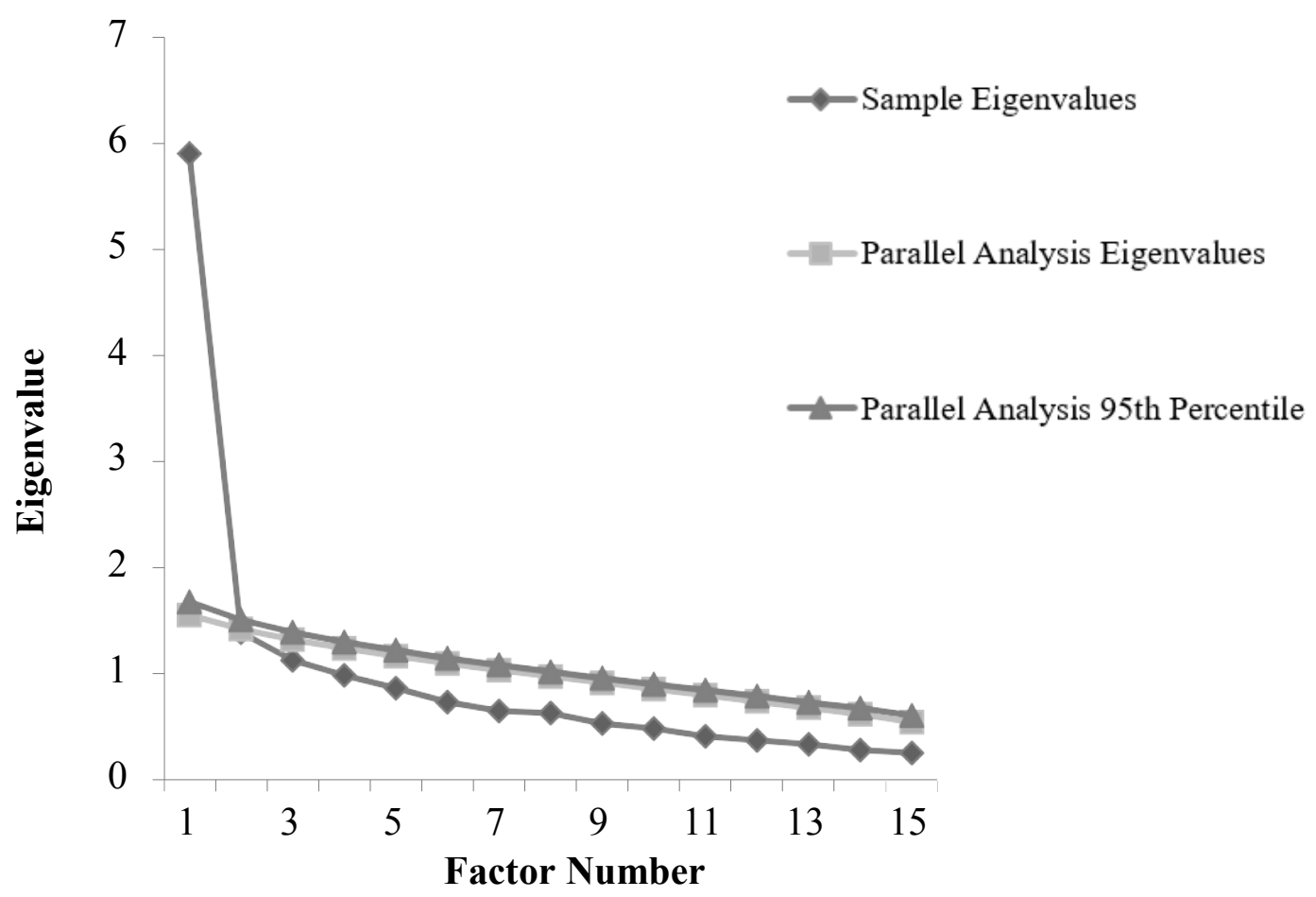

Figure 2. Horn's (1965) parallel analysis completed in Phase 1 on the 15-item PSEA scale. In this analysis, the number of factors can be estimated by comparing the eigenvalues from the data of this study to simulated eigenvalues. One thousand parallel analysis files were analyzed. The term "sample eigenvalues" refers to the eigenvalues that correspond to the data from this study. The term "parallel analysis eigenvalues" refers to the simulated eigenvalues at the 50th percentile (mean eigenvalues). The term "parallel analysis 95th percentile" refers to the simulated eigenvalues at the 95th percentile. 
POLICE SELF-EFFICACY

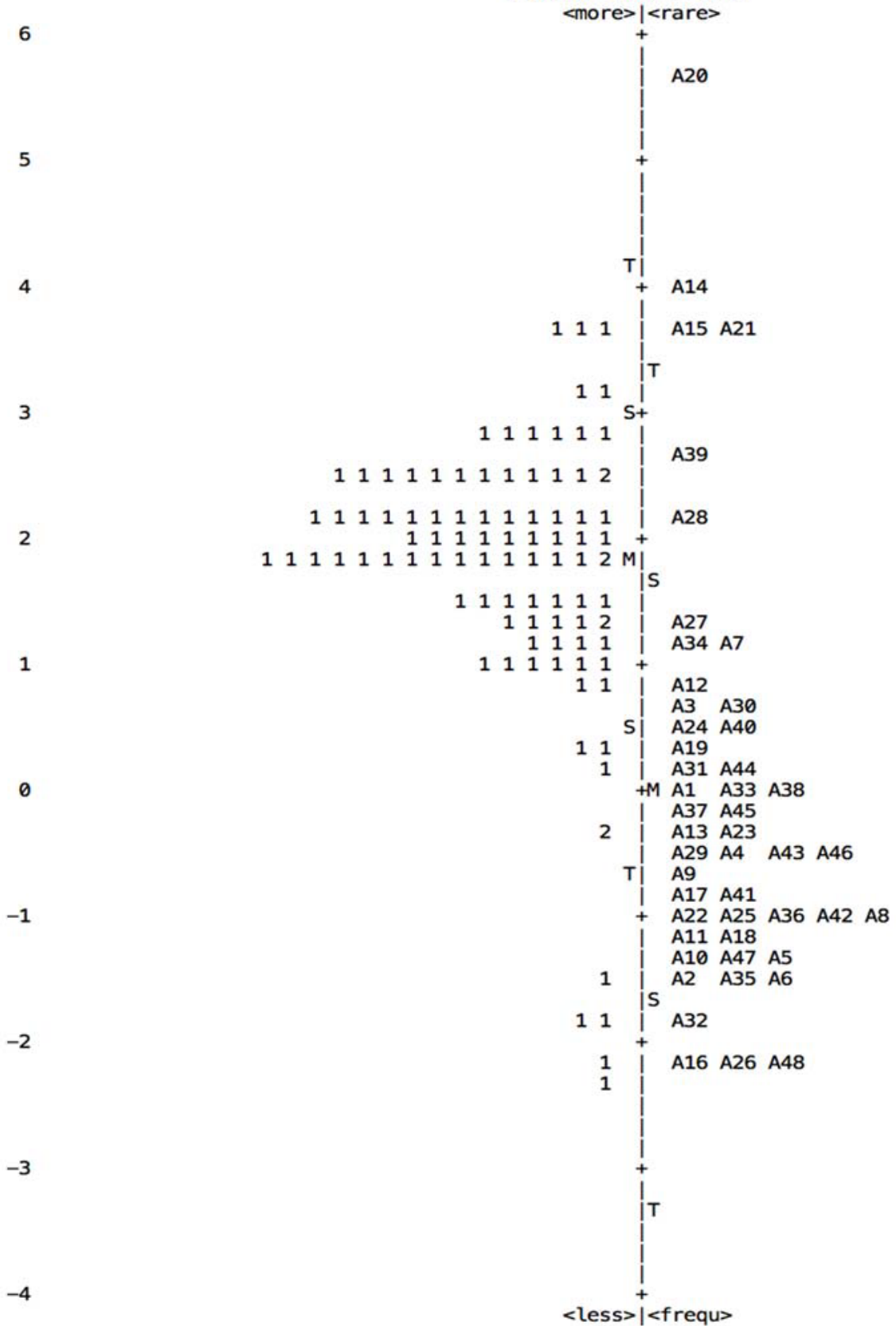

Figure 3. Phase 1 Wright Map from ASK-Q Rasch analysis. More difficult items are presented at the top of the map. Less difficult items are presented at the bottom of the map. Similarly, more knowledgeable police officers are at the top of the map, and less knowledgeable police officers are at the bottom of the map. A " 1 " is used to represent one participant. 
POLICE SELF-EFFICACY

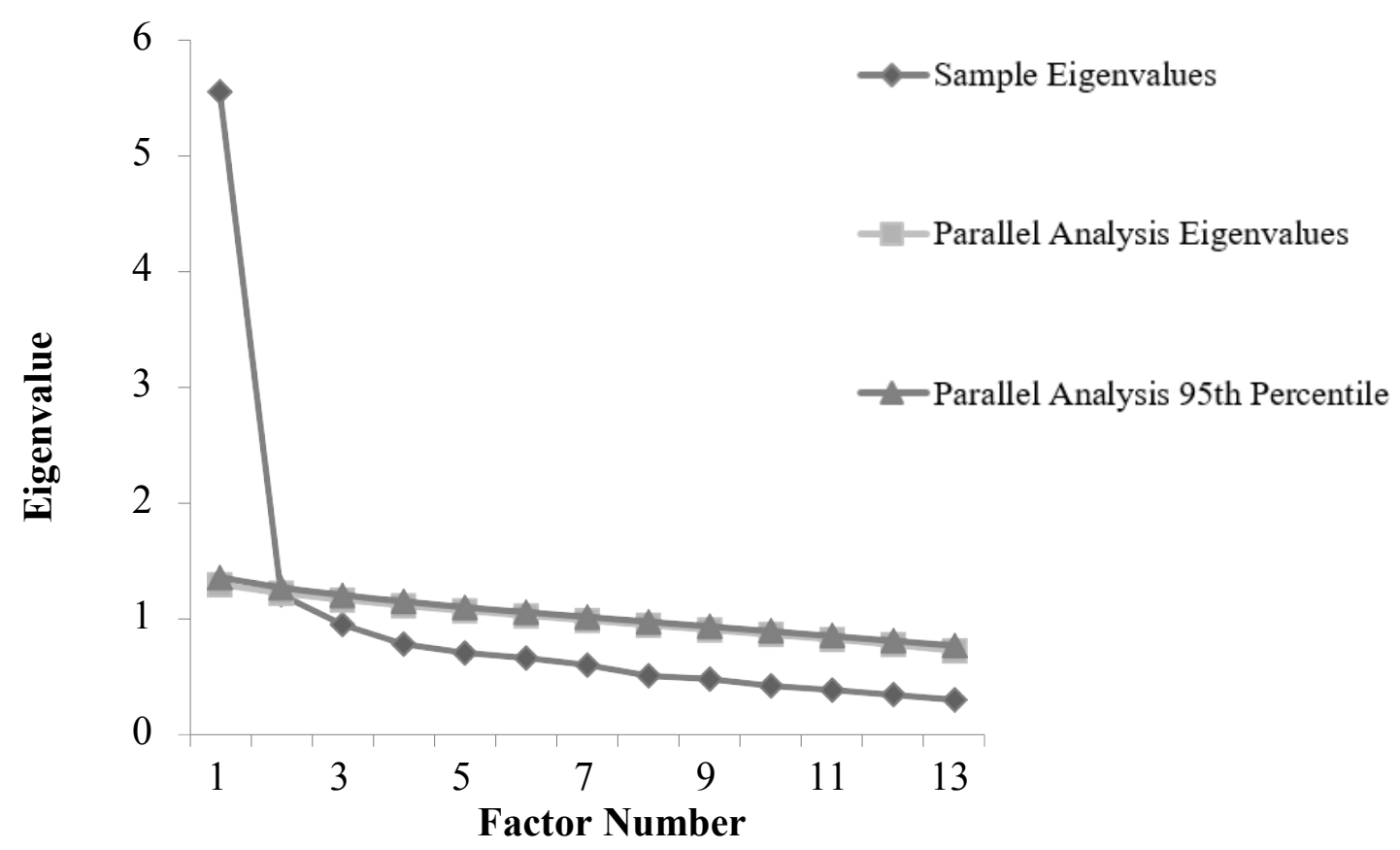

Figure 4. Horn's (1965) parallel analysis completed in Phase 2 on the 13-item PSEA scale. In this analysis, the number of factors can be estimated by comparing the eigenvalues from the data of this study to simulated eigenvalues. One thousand parallel analysis files were analyzed. The term "sample eigenvalues" refers to the eigenvalues that correspond to the data from this study. The term "parallel analysis eigenvalues" refers to the simulated eigenvalues at the 50th percentile (mean eigenvalues). The term "parallel analysis 95th percentile" refers to the simulated eigenvalues at the 95th percentile. 
POLICE SELF-EFFICACY

\section{Chapter 5: Discussion}

Bandura (1997) stated, "Analyses of how efficacy beliefs affect actions rely on microanalytic measures rather than global indices of personality traits or motives of effectance" (p. 14). The purpose of this study was to develop such a "microanalytic measure" that would be appropriate for assessing the self-efficacy of police officers when working with individuals with ASD. The final set of self-efficacy items was created based on a rigorous process that took into account the opinions of police officers, the recommendations of experts in $\mathrm{ASD}$, suggestions from experts in self-efficacy and psychometrics, and empirical evidence from two separate samples of police officers. Expert advice was gathered from police officers to ensure that the items were appropriate for this unique population of participants. Recommendations from experts in ASD were gathered because of the complex nature of this diagnosis. Even ASD experts may find it difficult to identify ASD in all individuals, and learning to interact appropriately with someone with ASD can be a challenging task. Therefore, ASD experts were consulted on this project to confirm that the items appropriately reflected the multifaceted nature of ASD. Finally, recommendations were collected from experts in self-efficacy and psychometrics to verify that the items reflected the construct of self-efficacy and were well-written.

Once the set of items was created, the scale was administered to an initial sample of police officers to gather empirical evidence (Phase 1). Several modifications were made and the scale was administered to a second sample of police officers (Phase 2) to gather further validity evidence. Results of this study revealed that the scale could be used to assess police officer self-efficacy for working with individuals with ASD, 


\section{POLICE SELF-EFFICACY}

although additional psychometric evidence should be gathered in future studies with diverse samples.

A descriptive analysis of the frequency distributions of the PSEA scale revealed that officers used Categories 3 ("Somewhat Agree") and 4 ("Strongly Agree") the most. Two items (e.g., Item 1 and Item 12) in particular highlighted this result, as less than 15 officers responded in Categories 1 and 2. This response could indicate that the officers answered the items in a self-enhancing or socially desirable way. Another possibility is that the response pattern reflects a selection bias in the sample. That is, officers who responded to the study invitation may have had greater familiarity with individuals with ASD and therefore were truly more self-efficacious for working with individuals with ASD. To understand more about these results and to ensure that the items on the PSEA scale discriminate between officers, additional item-level analyses (e.g., Rasch analyses) are recommended.

This study sought to explore additional psychometric properties of the police selfefficacy instrument (i.e., the PSEA scale) and the ASD knowledge scale (i.e., ASK-Q) as well as to analyze the association between the two measures. Results of both phases provided evidence that the items on the PSEA scale and the items on the ASK-Q reflected unidimensional constructs. A total score is appropriate for use when using the scales to measure the constructs of interest. This was specifically important for the ASKQ, as Harrison and colleagues (2017) had previously suggested that the ASK-Q items reflected a multidimensional construct.

Items on the ASK-Q were examined in more detail to ensure that all items contributed to the construct. Item 29 (“Autism is a communication disorder") was flagged 


\section{POLICE SELF-EFFICACY}

as a misfitting item in both phases. To understand the impact this item had on the overall scale, two correlation analyses were run - one that included the item (48-item ASK-Q) and one that excluded it (i.e., 47-item ASK-Q). Because there was no difference in the correlation results when using the 47-item ASK-Q and the original 48-item ASK-Q, the questionable item was retained. However, in future investigations, researchers can more critically examine this item's wording and contribution to the overall construct. A method such as cognitive interviewing could be used to understand how participants are responding to the item and offer suggestions for improvement in the wording or phrasing.

The association between self-efficacy and knowledge of ASD was also explored to gather evidence that both scales were functioning as expected. As hypothesized, results indicated that when officers reported more knowledge of ASD, they also reported higher levels of self-efficacy for working with individuals with ASD. The correlations were consistent in Phase 1 and Phase 2, although the coefficient obtained in Phase 2 was slightly higher. This could indicate that the changes made to the instrument between Phase 1 and Phase 2 helped to better capture the PSEA construct.

According to Bandura (1997), individuals do not only need the knowledge and skills to work with people with ASD, they also need belief in their own capabilities to demonstrate those skills. Knowledge and self-efficacy contribute to individuals' personal agency. In this study, officers who reported lower levels of self-efficacy for working with individuals with ASD were found to report less accurate knowledge of ASD. This finding is consistent with previous research in similar fields such as education (Lauermann \& König, 2016) and medicine (Rimal, 2000) where participants who reported more domainspecific knowledge also reported more domain-specific self-efficacy. Finding a consistent 


\section{POLICE SELF-EFFICACY}

association between these constructs as found in other fields (e.g., teaching and medicine) helps to demonstrate content validity for the newly developed self-efficacy instrument, providing evidence that the instrument is measuring the intended construct.

In Bandura's (1997) social cognitive theory, self-efficacy is considered a "generative capability," or one that drives a person to behave and execute skills under a variety of tasks (p. 36). Self-efficacy is a powerful self-evaluation that has been shown to influence how an individual might view a difficult task (Bandura, 1997). Police officers who report higher levels of self-efficacy for working with individuals with ASD may take on the task of working with this group of community members more readily than officers who feel they do not have the skills needed to work with such individuals. Although this study only provided a means of measuring police officer self-efficacy, the scale could be used in future explorations to test this hypothesis.

Interventions designed to increase knowledge of ASD have been a focus of recent international research (Harrison et al., 2016). However, this area of research is still novel and rigorous demonstrations of validity and reliability have not yet been provided for most established measures of ASD knowledge (Harrison et al., 2017). Use of the PSEA scale could lead to more detailed understanding of officer self-efficacy, and this understanding may help to generate effective training programs. The PSEA scale may be useful in police training programs because it can help researchers understand more about officers' capability judgments. The scale can also inform trainings designed to improve officer knowledge and self-efficacy. "Police departments . . may benefit from brief, easy-to-conduct evaluations to ensure that they are achieving goals set at initial implementation. All too often, programs with such goals in mind are implemented but not 


\section{POLICE SELF-EFFICACY}

evaluated to demonstrate effectiveness, which may be vital to ensure that sustained support and program funding” (Broussard et al., 2011, p. 461). Self-efficacy and knowledge can be measured before and after educational opportunities to understand the effectiveness of the training program.

Police officers' efficacy beliefs can affect whether they will change their behavior and whether they will be motivated to persevere in a new situation (Bandura, 1997). For example, if an officer were to conduct a traffic stop involving an individual with ASD and correctly suspect the individual's diagnosis, then she may be able to more effectively handle the situation if she has a positive belief in her own capabilities for working with individuals with ASD. The association between self-efficacy and the behavior of police officers, however, has yet to be explored. Currently, the hypothesis that police officer self-efficacy for working with individuals with ASD will affect police officer behavior is theoretical, based on Bandura's (1986) social cognitive theory. This dissertation provides initial psychometric evidence for the scale and allows for future explorations of this kind.

\section{Summary of Future Research}

This study gives way to three promising areas for future research. First, studies are needed to confirm the psychometric properties of the PSEA scale. Additional sources of validity evidence, including analyses based on convergent and discriminant evidence, will be helpful in situating police self-efficacy for working with individuals with ASD among other constructs. For example, stress and burnout, two outcomes that are readily examined in policing (e.g., Anshel, 2000; Burke, 1993; McCarty, Aldirawi, Dewald, \& Palacios, 2019), have been studied alongside self-efficacy in other occupational spheres. In education, teachers who report low levels of self-efficacy have been shown to report 


\section{POLICE SELF-EFFICACY}

greater teacher stress and burnout (Brouwers \& Tomic, 2001; Ruble et al., 2013;

Schwarzer \& Hallum, 2008). Teacher self-efficacy is also associated with improved classroom management techniques such as the ability promote positive strategies to deal with challenging behavior (Brouwers \& Tomic, 2001). Similar relationships need to be studied to determine whether police officer self-efficacy is associated with decreased stress, minimized burnout, and improved ability to work with challenging behaviors, a crucial skill when working with persons with ASD in unpredictable emergency situations. Further validity evidence could be gathered to address the appropriateness of this instrument for more diverse samples, such as police officer recruits or criminal justice students. Providing validity evidence from measurement invariance studies that compare the construct across groups can help to determine the limits and appropriateness of the PSEA scale for other samples.

Second, a key next step is to determine the extent to which police officer selfefficacy for working with individuals with ASD is associated with actual police behavior (e.g., how often officers successfully interact with someone with ASD). According to social cognitive theory, reciprocal interactions among environmental, behavioral, and personal factors can explain human functioning (Bandura, 1986). Both knowledge and self-efficacy would be categorized as personal factors that likely influence police officer behavior. Bandura (1986) and other social cognitive theorists contended that people have a capacity for self-influence and personal control, which suggests that personal factors, such as beliefs, play a role in determining behavior in the diverse circumstances individuals face (Bandura, 1997). Therefore, I hypothesize that police officers who report high levels of self-efficacy feel more in control when working in challenging situations 


\section{POLICE SELF-EFFICACY}

involving individuals with ASD and are more likely to utilize effective strategies. However, this relationship has yet to be tested, as a system does not exist that would allow for the analysis of the interactions between police officers and individuals with ASD in their communities. Researchers could gather data on police behavior by selfreport (e.g., asking police officers to provide frequency estimations for various interactions with individuals with ASD), by simulation (e.g., asking police officers to respond to simulated scenarios involving individuals with ASD), or by secondary data provided by departments on officers' interactions with individuals with ASD.

Third, the PSEA scale can be useful for determining the effectiveness of an intervention designed to support police officers in their work with individuals with ASD. Modell and Mak (2008) found that police officers in their study agreed with the need for more officer training about interacting with community members with disabilities of all types, and recent popular news coverage of incidents with police officers and individuals with ASD has raised the attention of police departments to the importance of these training opportunities. Initial findings from two studies demonstrated the importance of ASD-specific trainings and the potential to improve police officer knowledge of ASD and confidence in interacting with people with ASD (e.g., Teagardin, Dixon, Smith, \& Granpeesheh, 2012). Many states are making such trainings mandatory, and measures that are based on psychometric evidence will help to evaluate their effectiveness.

Once the trainings are rigorously designed, a change in officers' capability judgments can serve as evidence of intervention efficacy, as demonstrated in studies in related fields (e.g., Sheeran et al., 2016). That is, researchers could assess the extent to which trainings help officers feel more capable and skilled in their interactions with 


\section{POLICE SELF-EFFICACY}

individuals with ASD. After further validity testing including a confirmatory factor analysis, the scale can be used before and after the training to help educators assess the change in how capable officers feel interacting with individuals with ASD in their communities.

\section{Limitations}

This dissertation was an initial scale development study for an instrument designed to measure police officer self-efficacy for working with individuals with ASD. The work was limited in several ways. First, this study relied entirely on the use of selfreport data, which can be influenced by social desirability, or a participant's tendency to answer the items in the way she feels is socially appropriate. In addition, recruitment for this study was not at random and the participants who took the survey may not be representative of the broader population of police officers in the United States. For example, as noted above, police officers were told the study was about police officers and individuals with ASD. Because officers could choose to respond, it is possible that only officers who knew something about ASD responded, which limits the external validity of this study. To avoid this potential bias, the PSEA scale could be sent out to police officers at random to better reflect the whole population of officers across the United States. To overcome the convenience sample, the exploratory factor analysis was repeated in two phases, which is an acceptable method for increasing generalizability of results (DeVellis, 2012).

Finally, the response rate within police departments who agreed to participate was low (often less than 10\%). Although common among studies seeking self-reports (Sheehan, 2001) and with electronic and web surveys (Fan \& Yan, 2010), this low 


\section{POLICE SELF-EFFICACY}

response rate could have biased the results of this study. The incentive for survey distribution was targeted at police chiefs, as participating departments were offered a free training in exchange for sending out the survey to their officers. An incentive that targeted the officers may have been more effective in increasing the participation rate. Officers who knew someone with ASD or felt confident in their own self-efficacy for working with individuals with ASD may have been more likely to respond. Officers who were less experienced or who were concerned about their knowledge of ASD may have ignored the survey request. Collecting data in person where all police officers are instructed to take the survey at once may have decreased this bias by ensuring full participation, as opposed to volunteer participation.

\section{Concluding Remarks}

An article from Phoenix, Arizona, on September 19, 2017, detailed an incident in which a police officer detained an individual with ASD because he misinterpreted his behaviors and believed the individual's rigid and unfamiliar movements were a sign of drug intoxication. The bodycam captured footage of the exchange between the officer and individual, and the family released photos of the boy's injuries from the brief detainment (Helsel, 2017). A more serious incident involving a shooting occurred in 2016 in Florida when a young person with ASD was getting assistance from his caretaker in the street and both a community member and officer misinterpreted the individual as being "armed and suicidal" (Silberman, 2017). Unfortunately, these incidents are not anomalies, and simple interactions between police officers and individuals with ASD are becoming news headlines because of a misinterpretation of behaviors. The PSEA scale was designed in response to these incidents as a tool to measure officer beliefs that they 
POLICE SELF-EFFICACY

can effectively work with this group of community members. It is worthwhile to pursue research that directly measures police officer beliefs about working with individuals with ASD to help design and understand police training effectiveness, planned as a proactive response to incidents like this across the country. 
Appendix A

The Police Self-Efficacy for Autism (PSEA) Scale: Phase 1

The following items are designed to help us understand more about what might be difficult for a police officer when working with a person with autism on the job. We are interested in your own personal judgments, so please answer by considering your own capabilities at this point in your career as a police officer.

When working as a police officer ...

PSEA1 I can identify some signs of autism when I observe them

PSEA2 I can de-escalate a situation in which a person with autism is harming others.

PSEA3 I can de-escalate a situation in which a person with autism is harming himself or herself.

PSEA4 I can explain at least three general characteristics of a person with autism to another police officer who asks.

PSEA5 I can distinguish autism from other disabilities.

PSEA6 I can recognize which of the behaviors below are frequently associated with autism:

- Hearing voices

- Avoidance of eye contact

- Lack of balance

- Repetitive body motions

- Slurred speech

PSEA7 I can correctly identify which of the following are common in people with autism:

- Communication challenges

- Mental illness

- Social anxiety

- Physical impairment

- Intellectual disability

PSEA8 I can tell the difference between someone who has autism and someone who is demonstrating drug-induced behavior.

PSEA9 I can adapt the way I communicate to explain something to a person with autism.

PSEA10 I can establish rapport with someone who has autism.

PSEA11 I can use what I know about autism to help find an individual with autism who has become a missing person.

PSEA12 I can seek appropriate information from a caregiver when trying to learn more about someone with autism.

PSEA13 I can look for an ID when I cannot get personal information verbally from an individual with autism.

PSEA14 I can inform a concerned citizen about autism.

PSEA15 I can modify the environment to help an individual with autism feel calm during an emergency.

\section{Response Format}

Strongly Disagree Somewhat Disagree Somewhat Agree Strongly Agree 
POLICE SELF-EFFICACY

\section{Appendix B}

Demographic Survey

1. Age (in years):

2. Gender: Male Female Other(specify):

3. Which of the following describes you best?

\author{
White \\ Latino/Hispanic \\ Native Hawaiian/Pacific Islander \\ Native

White
Latino/Hispanic
Native Hawaiian/Pacific Islander \\ Two or more races
}

4. Highest level of education completed:

High school diploma GED

Associate's degree
Asian Black/African American American Indian/Alaska

Other:

5. For the purpose of this study, we will be defining recruit officers as those who have no previous experience with policing and veteran officers as those who are currently working as law enforcement officers. Please select which category best represents your current level of experience: Veteran Recruit Other (specify):

6. Current rank: (If you are in training as a recruit, please write "in training")

7. Regarding your personal life - Do you know someone with ASD?
a. No
b. Yes - 1 person
c. Yes - 2 people
d. Yes - More than 2 people

8. How do you know them?
a. Immediate family member
b. Extended family member
c. Friend
d. Other 
9. Regarding your professional life - Have you encountered individuals with ASD?
a. Yes
b. No

10. How often do you encounter individuals with ASD?
a. Daily
b. Weekly
c. Once a month
d. Once a year
e. Other:

11. How many hours of training have you received on how to serve individuals with disabilities? (as a police officer in training or through professional development):

12. How many hours of training have you received on how to serve individuals with autism spectrum disorder? (as a police officer in training or through professional development)

13. Please share any other information that you believe is relevant or related to your experience and knowledge of persons with ASD. 


\section{Appendix C \\ Expert Review Sample Item}

You are being invited to participate in this survey as an expert reviewer. The survey will take approximately 15 minutes to complete; however, your feedback is a critical step toward providing insight into the development of this instrument. You will be asked to read one item at a time that is being considered for a self-efficacy instrument measuring police self-efficacy for working with individuals with Autism Spectrum Disorder (ASD). After each item, you will have the opportunity to rate the item for quality and clarity as well as the adherence to your area of expertise. You may provide additional item-level feedback if you would like.

A consent form approved by the University of Kentucky's institutional review board will proceed the questions.

Item 1: "I can use an alternative communication strategy when speaking with someone with ASD who has limited verbal communication."

\begin{tabular}{l|cccc} 
Very & Somewhat & Somewhat & Very \\
Unclear & Unclear & Clear & Clear
\end{tabular}

This item is clear.

$\begin{array}{cccc}\text { Not } & \text { Slightly } & \text { Moderately } & \text { Very } \\ \text { Important } & \text { Important } & \text { Important }\end{array}$

This item is important when considering the needs of someone with ASD.

\begin{tabular}{c|cccc} 
& $\begin{array}{c}\text { Very } \\
\text { Unrealistic }\end{array}$ & $\begin{array}{c}\text { Somewhat } \\
\text { Unrealistic }\end{array}$ & $\begin{array}{c}\text { Somewhat } \\
\text { Realistic }\end{array}$ & $\begin{array}{r}\text { Very } \\
\text { Realistic }\end{array}$ \\
\hline $\begin{array}{c}\text { This item is realistic } \\
\text { when considering the } \\
\text { duties of a police officer. }\end{array}$ & 0 & & & \\
\hline
\end{tabular}

Please use this opportunity to provide additional feedback on your "Item 1" ratings: 
Appendix D

Item Modification Process

\begin{tabular}{|c|c|c|c|c|c|}
\hline $\begin{array}{c}\text { Step 1: } \\
\text { Original Item }\end{array}$ & $\begin{array}{c}\text { Step 2: } \\
\text { Expert Review \& } \\
\text { Focus Group }\end{array}$ & $\begin{array}{c}\text { Step 3: } \\
\text { Expert Review }\end{array}$ & $\begin{array}{c}\text { Step 4: } \\
\text { Cognitive } \\
\text { Interview }\end{array}$ & $\begin{array}{c}\text { Step 5: } \\
\text { Expert Review }\end{array}$ & $\begin{array}{c}\text { Step 6: } \\
\text { Empirical } \\
\text { Evidence } \\
\end{array}$ \\
\hline $\begin{array}{l}\text { I can use an } \\
\text { alternative } \\
\text { communication } \\
\text { strategy when } \\
\text { speaking with } \\
\text { someone with ASD } \\
\text { who has limited } \\
\text { verbal } \\
\text { communication. }\end{array}$ & $\begin{array}{l}\text { Deleted: redundant } \\
\text { with PSEA7 }\end{array}$ & & & & \\
\hline $\begin{array}{l}\text { I can deescalate a } \\
\text { situation with an } \\
\text { individual with ASD } \\
\text { who is harming their } \\
\text { caregiver. }\end{array}$ & $\begin{array}{l}\text { Modified: I can } \\
\text { deescalate a situation } \\
\text { where a person with } \\
\text { ASD is upset and } \\
\text { harming his caregivers }\end{array}$ & $\begin{array}{l}\text { Modified: I can } \\
\text { deescalate a situation } \\
\text { where a person with } \\
\text { ASD is upset and } \\
\text { harming himself or } \\
\text { others. }\end{array}$ & No change & $\begin{array}{l}\text { Modified: I can de- } \\
\text { escalate a situation } \\
\text { in which a person } \\
\text { with autism is } \\
\text { harming others. }\end{array}$ & $\begin{array}{l}\text { Item retained for } \\
\text { final scale }\end{array}$ \\
\hline $\begin{array}{l}\text { I can calm down a } \\
\text { person with ASD who } \\
\text { is having a behavioral } \\
\text { meltdown. }\end{array}$ & $\begin{array}{l}\text { Modified: I can } \\
\text { support a person with } \\
\text { ASD when he or she is } \\
\text { demonstrating } \\
\text { significant behavioral } \\
\text { challenges }\end{array}$ & $\begin{array}{l}\text { Deleted: Terminology } \\
\text { was determined to be } \\
\text { too advanced for } \\
\text { someone that does not } \\
\text { know anything about } \\
\text { ASD }\end{array}$ & & $\mathrm{N} / \mathrm{A}$ & \\
\hline
\end{tabular}




\begin{tabular}{|c|c|c|c|c|c|}
\hline $\begin{array}{c}\text { Step 1: } \\
\text { Original Item }\end{array}$ & $\begin{array}{c}\text { Step 2: } \\
\text { Expert Review \& } \\
\text { Focus Group }\end{array}$ & $\begin{array}{c}\text { Step 3: } \\
\text { Expert Review }\end{array}$ & $\begin{array}{c}\text { Step 4: } \\
\text { Cognitive } \\
\text { Interview }\end{array}$ & $\begin{array}{c}\text { Step 5: } \\
\text { Expert Review }\end{array}$ & $\begin{array}{c}\text { Step 6: } \\
\text { Empirical } \\
\text { Evidence }\end{array}$ \\
\hline I can interact with & Deleted: Too broad & \multicolumn{4}{|c|}{$\mathrm{N} / \mathrm{A}$} \\
\hline $\begin{array}{l}\text { I can tell another } \\
\text { officer how to } \\
\text { identify if someone } \\
\text { has ASD. }\end{array}$ & $\begin{array}{l}\text { Modified: I can } \\
\text { explain the } \\
\text { characteristics of a } \\
\text { person with ASD to } \\
\text { another police officer. }\end{array}$ & $\begin{array}{l}\text { Modified: I can } \\
\text { explain at least three } \\
\text { general characteristics } \\
\text { of a person with } \\
\text { autism to another } \\
\text { police officer. }\end{array}$ & No change & $\begin{array}{l}\text { Modified: I can } \\
\text { explain at least three } \\
\text { general } \\
\text { characteristics of a } \\
\text { person with autism } \\
\text { to another police } \\
\text { officer who asks. }\end{array}$ & $\begin{array}{l}\text { Item retained for } \\
\text { final scale }\end{array}$ \\
\hline $\begin{array}{l}\text { I can talk to someone } \\
\text { who has ASD. }\end{array}$ & $\begin{array}{l}\text { Modified: I can } \\
\text { communicate } \\
\text { effectively with } \\
\text { someone who has } \\
\text { ASD. }\end{array}$ & $\begin{array}{l}\text { Modified: I can } \\
\text { communicate with } \\
\text { someone who has } \\
\text { autism. }\end{array}$ & $\begin{array}{l}\text { Delete: Item is too } \\
\text { broad and similar } \\
\text { to other item }\end{array}$ & \multicolumn{2}{|c|}{$\mathrm{N} / \mathrm{A}$} \\
\hline $\begin{array}{l}\text { I can recognize when } \\
\text { a person is } \\
\text { "stimming." }\end{array}$ & No change & $\begin{array}{l}\text { Modified: I can } \\
\text { recognize when a } \\
\text { person with autism is } \\
\text { stimming. }\end{array}$ & $\begin{array}{l}\text { Modified: I can } \\
\text { recognize when a } \\
\text { person with autism } \\
\text { is stimming for } \\
\text { self-regulation } \\
\text { (e.g., flapping } \\
\text { hands, pacing back } \\
\text { and forth) }\end{array}$ & $\begin{array}{l}\text { Delete: Item was } \\
\text { determined to be too } \\
\text { difficult for police } \\
\text { officers to interpret } \\
\text { without a prior } \\
\text { knowledge of } \\
\text { stimming. }\end{array}$ & N/A \\
\hline
\end{tabular}




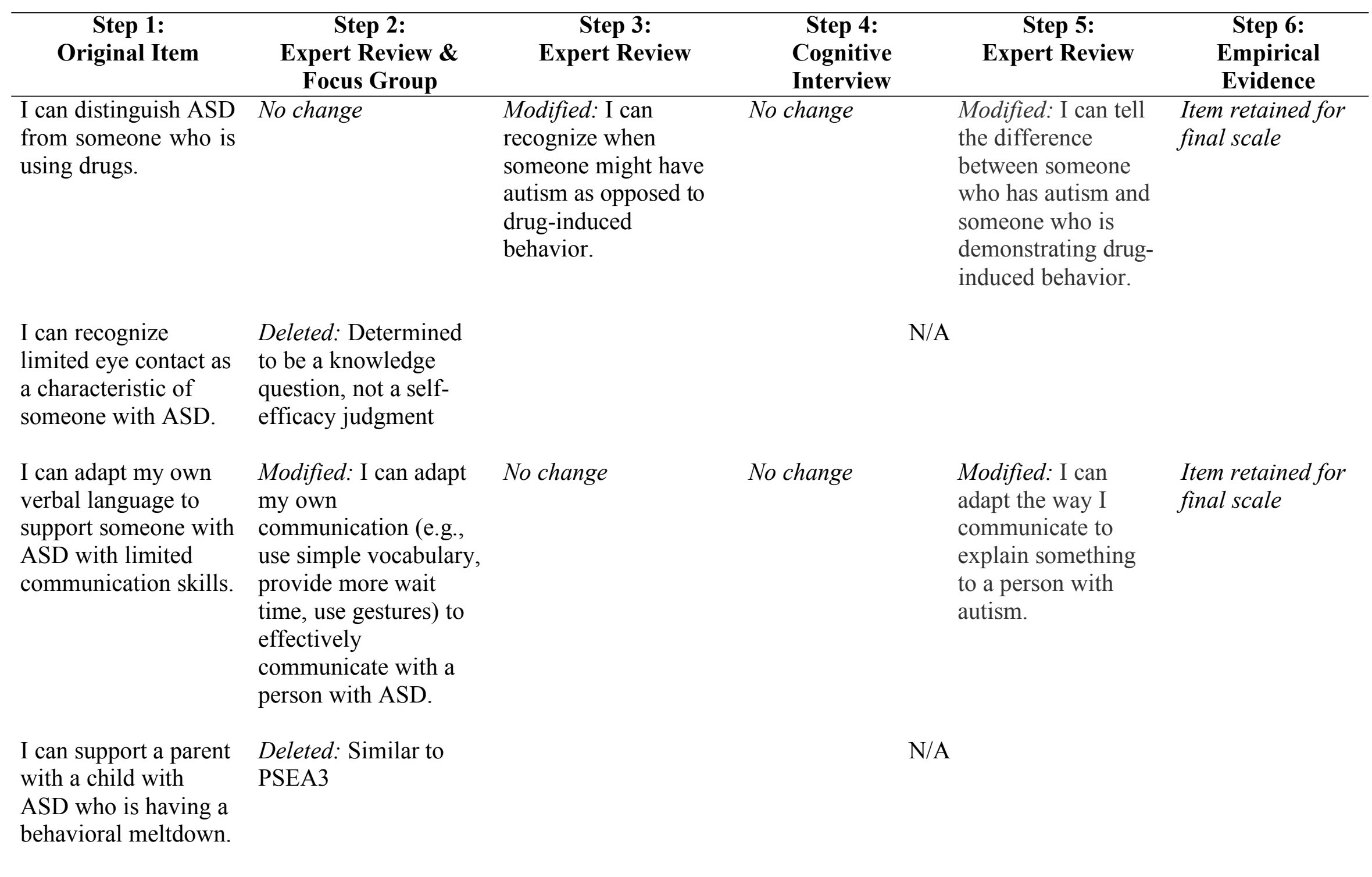




\begin{tabular}{|c|c|c|c|c|c|}
\hline $\begin{array}{c}\text { Step 1: } \\
\text { Original Item }\end{array}$ & $\begin{array}{c}\text { Step 2: } \\
\text { Expert Review \& } \\
\text { Focus Group }\end{array}$ & $\begin{array}{c}\text { Step 3: } \\
\text { Expert Review }\end{array}$ & $\begin{array}{c}\text { Step 4: } \\
\text { Cognitive } \\
\text { Interview }\end{array}$ & $\begin{array}{c}\text { Step 5: } \\
\text { Expert Review }\end{array}$ & $\begin{array}{c}\text { Step 6: } \\
\text { Empirical } \\
\text { Evidence }\end{array}$ \\
\hline $\begin{array}{l}\text { I can use an } \\
\text { individual's special } \\
\text { interest to connect } \\
\text { with someone with } \\
\text { ASD. }\end{array}$ & $\begin{array}{l}\text { Modified: I can } \\
\text { establish rapport with } \\
\text { an individual with } \\
\text { ASD. }\end{array}$ & $\begin{array}{l}\text { Modified: I can } \\
\text { establish rapport with } \\
\text { someone with autism. }\end{array}$ & No change & $\begin{array}{l}\text { Modified: I can } \\
\text { establish rapport } \\
\text { with someone who } \\
\text { has autism. }\end{array}$ & $\begin{array}{l}\text { Item retained for } \\
\text { final scale }\end{array}$ \\
\hline $\begin{array}{l}\text { I can seek appropriate } \\
\text { information from a } \\
\text { caregiver when trying } \\
\text { to learn more about } \\
\text { someone with ASD. }\end{array}$ & No change & No change & No change & No change & $\begin{array}{l}\text { Item retained for } \\
\text { final scale }\end{array}$ \\
\hline Written in Step 2 & $\begin{array}{l}\text { New Item: I can look } \\
\text { for an ID (e.g., } \\
\text { bracelet, shoe tag, } \\
\text { wallet ID) when I } \\
\text { cannot get a person's } \\
\text { personal information } \\
\text { verbally. }\end{array}$ & No change & No change & $\begin{array}{l}\text { Modified: I can look } \\
\text { for an ID when I } \\
\text { cannot get personal } \\
\text { information verbally } \\
\text { from an individual } \\
\text { with autism. }\end{array}$ & $\begin{array}{l}\text { Modified: I can } \\
\text { gather identifying } \\
\text { information from } \\
\text { someone with } \\
\text { autism who does } \\
\text { not use verbal } \\
\text { speech. }\end{array}$ \\
\hline
\end{tabular}




\begin{tabular}{|c|c|c|c|c|c|}
\hline $\begin{array}{c}\text { Step 1: } \\
\text { Original Item }\end{array}$ & $\begin{array}{c}\text { Step 2: } \\
\text { Expert Review \& } \\
\text { Focus Group }\end{array}$ & $\begin{array}{c}\text { Step 3: } \\
\text { Expert Review }\end{array}$ & $\begin{array}{c}\text { Step 4: } \\
\text { Cognitive } \\
\text { Interview }\end{array}$ & $\begin{array}{c}\text { Step 5: } \\
\text { Expert Review }\end{array}$ & $\begin{array}{c}\text { Step 6: } \\
\text { Empirical } \\
\text { Evidence }\end{array}$ \\
\hline Written in Step 2 & $\begin{array}{l}\text { New Item: I can talk to } \\
\text { a concerned citizen } \\
\text { about ASD. }\end{array}$ & No change & No change & $\begin{array}{l}\text { Modified: I can } \\
\text { inform a concerned } \\
\text { citizen about autism. }\end{array}$ & $\begin{array}{l}\text { Item retained for } \\
\text { final scale }\end{array}$ \\
\hline Written in Step 2 & $\begin{array}{l}\text { New Item: I can } \\
\text { modify the } \\
\text { environment (e.g., find } \\
\text { a quiet location, turn } \\
\text { down sirens) to help } \\
\text { an individual with } \\
\text { ASD feel calm during } \\
\text { an emergency. }\end{array}$ & $\begin{array}{l}\text { Modified: During an } \\
\text { emergency, I can } \\
\text { modify the } \\
\text { environment (e.g., find } \\
\text { a quiet location, turn } \\
\text { down lights and } \\
\text { sirens) to help an } \\
\text { individual feel calm }\end{array}$ & No change & $\begin{array}{l}\text { Modified: I can } \\
\text { modify the } \\
\text { environment to help } \\
\text { an individual with } \\
\text { autism feel calm } \\
\text { during an } \\
\text { emergency. }\end{array}$ & $\begin{array}{l}\text { Item retained for } \\
\text { final scale }\end{array}$ \\
\hline
\end{tabular}




\begin{tabular}{|c|c|c|c|c|c|}
\hline $\begin{array}{c}\text { Step 1: } \\
\text { Original Item }\end{array}$ & $\begin{array}{c}\text { Step 2: } \\
\text { Expert Review \& } \\
\text { Focus Group }\end{array}$ & $\begin{array}{c}\text { Step 3: } \\
\text { Expert Review }\end{array}$ & $\begin{array}{c}\text { Step 4: } \\
\text { Cognitive } \\
\text { Interview }\end{array}$ & $\begin{array}{c}\text { Step 5: } \\
\text { Expert Review }\end{array}$ & $\begin{array}{c}\text { Step 6: } \\
\text { Empirical } \\
\text { Evidence }\end{array}$ \\
\hline Written in Step 3 & Written in Step 3 & $\begin{array}{l}\text { I can recognize which } \\
\text { of the behaviors below } \\
\text { are frequently } \\
\text { associated with } \\
\text { autism: } \\
\text { - Hearing voices } \\
\text { - Avoidance of eye } \\
\text { contact } \\
\text { - Lack of balance } \\
\text { - Repetitive body } \\
\text { motions } \\
\text { Slurred speech }\end{array}$ & No change & No change & $\begin{array}{l}\text { Deleted: Item } \\
\text { format was } \\
\text { reviewed by a } \\
\text { team of experts } \\
\text { and determined to } \\
\text { be double } \\
\text { barreled (i.e., } \\
\text { asking officers to } \\
\text { consider more } \\
\text { than one concept) }\end{array}$ \\
\hline Written in Step 3 & Written in Step 3 & $\begin{array}{l}\text { I can correctly identify } \\
\text { which of the following } \\
\text { are common in people } \\
\text { with autism: } \\
\text { - Communication } \\
\text { challenges } \\
\text { - Mental illness } \\
\text { - Social anxiety } \\
\text { - Physical } \\
\text { impairment } \\
\text { - Intellectual } \\
\text { disability }\end{array}$ & No change & No change & $\begin{array}{l}\text { Deleted: Item } \\
\text { format was } \\
\text { reviewed by a } \\
\text { team of experts } \\
\text { and determined to } \\
\text { be double } \\
\text { barreled and } \\
\text { asking officers } \\
\text { more than one } \\
\text { thing }\end{array}$ \\
\hline
\end{tabular}


Appendix E

Autism Knowledge Questionnaire (ASK-Q)

For each question, please choose the option that best matches your current beliefs and understanding about autism spectrum disorders

Agree

(1)

(Agree/Disagree). Please circle only one option for each question.

Thank you for your time!

1. I have heard of autism.

2. Some children with autism may lose acquired speech.

3. Children with autism may have strange reactions to the way things smell, taste, look, feel, or sound.

4. Many children with autism have trouble understanding facial expressions.

5. We now have treatments that can cure autism.

6. It is important that children diagnosed with autism receive some form of special education services at school.

7. Some children with autism do not talk.

8. Medication can alleviate the core symptoms of autism.

9. There is currently no cure for autism.

10. Autism happens mostly in middle class families.

11. Autism is preventable.

12. Many children with autism have trouble tolerating loud noises or certain types of touch.

13. Autism is more frequently diagnosed in males than females.

14. Children with autism can grow up to live independently.

15. All children with autism usually have problems with aggression.

16. Autism affects people of all races and ethnicities.

17. Children with autism need extra help to learn.

18. Children with autism are never too old to benefit from treatment.

19. The earlier the treatment of autism starts, the more effective it tends to be.

20. Children with autism do not enjoy the presence of others.

21. Most children with autism are also intellectually disabled.

22. Many children with autism show the need for routines and sameness.

23. Vaccinations cause autism.

24. Most children with autism are extremely impaired and cannot live independently as adults

25. Most children with autism may not look at things when you point at them.

26. Some children with autism show intense interest in parts of objects.

27. Autism is the result of a curse or evil eye put upon/inflicted on the family.

28. Many children with autism repeatedly spin objects or flap their arms.

1

1

Disagree

(0)

0

0

\begin{tabular}{l|l}
1 & 0 \\
1 & 0
\end{tabular}

$1 \quad 0$

$1 \quad 0$

10

$1 \quad 0$

$1 \quad 0$

10

10

10

0

0

0

(

(0)

(1)

(

(

(


29. Autism is a communication disorder.

30. Autism occurs more commonly among higher socioeconomic and educational levels.

31. Autism is a developmental disorder.

32. Behavior therapy is an intervention most likely to be effective for children with autism.

33. Early intervention can lead to significant gains in children with autism's social and communication skills.

34. Autism can be diagnosed as early as 18 months.

35. A lot of children with autism have problems with being aggressive or hyperactive.

36. Children with autism cannot learn any social skill.

37. Many times children with autism get excessively focused on one thing.

38. Many children with autism have difficulty using everyday language to communicate their needs.

39. Early intervention demonstrates no additional benefit to children with autism.

40. There is currently no medical test to diagnose autism.

41. Traumatic experiences very early in life can cause autism.

42. The number of diagnosed cases of autism has increased over the past 10 years.

43. Without proper treatment, most children diagnosed with autism eventually outgrow the disorder.

44. Autism is something that is very rare.

45. Autism is caused by God or a supreme being.

46. Autism is a brain-based disorder.

47. The cause of autism is not yet known for sure.

48. Many children with autism get upset if their routine is changed.

49. Autism is due to cold, rejecting parents.

\begin{tabular}{|c|c|}
\hline 1 & 0 \\
\hline 1 & 0 \\
\hline 1 & 0 \\
\hline 1 & 0 \\
\hline 1 & 0 \\
\hline 1 & 0 \\
\hline 1 & 0 \\
\hline 1 & 0 \\
\hline 1 & 0 \\
\hline 1 & 0 \\
\hline 1 & 0 \\
\hline 1 & 0 \\
\hline 1 & 0 \\
\hline 1 & 0 \\
\hline 1 & 0 \\
\hline 1 & 0 \\
\hline 1 & 0 \\
\hline 1 & 0 \\
\hline 1 & 0 \\
\hline 1 & 0 \\
\hline 1 & 0 \\
\hline
\end{tabular}




\section{Appendix F}

Polychoric Correlation Matrix for PSEA Items in Phase 1

\begin{tabular}{|c|c|c|c|c|c|c|c|c|c|c|c|c|c|c|}
\hline & $\begin{array}{c}\text { PSEA } \\
1 \\
\end{array}$ & $\begin{array}{c}\text { PSEA } \\
2 \\
\end{array}$ & $\begin{array}{c}\text { PSEA } \\
3 \\
\end{array}$ & $\begin{array}{c}\text { PSEA } \\
4 \\
\end{array}$ & $\begin{array}{c}\text { PSEA } \\
5 \\
\end{array}$ & $\begin{array}{c}\text { PSEA } \\
6\end{array}$ & $\begin{array}{c}\text { PSEA } \\
7 \\
\end{array}$ & $\begin{array}{c}\text { PSEA } \\
8 \\
\end{array}$ & $\begin{array}{c}\text { PSEA } \\
9 \\
\end{array}$ & $\begin{array}{c}\text { PSEA } \\
10 \\
\end{array}$ & $\begin{array}{c}\text { PSEA } \\
11 \\
\end{array}$ & $\begin{array}{c}\text { PSEA } \\
12 \\
\end{array}$ & $\begin{array}{c}\text { PSEA } \\
13 \\
\end{array}$ & $\begin{array}{c}\text { PSEA } \\
14 \\
\end{array}$ \\
\hline PSEA2 & .41 & & & & & & & & & & & & & \\
\hline PSEA3 & .46 & .72 & & & & & & & & & & & & \\
\hline PSEA4 & .68 & .29 & .32 & & & & & & & & & & & \\
\hline PSEA5 & .62 & .52 & .52 & .54 & & & & & & & & & & \\
\hline PSEA6 & .66 & .44 & .45 & .57 & .70 & & & & & & & & & \\
\hline PSEA7 & .72 & .32 & .46 & .56 & .57 & .59 & & & & & & & & \\
\hline PSEA8 & .52 & .24 & .38 & .27 & .55 & .43 & .52 & & & & & & & \\
\hline PSEA9 & .52 & .54 & .57 & .38 & .50 & .40 & .57 & .50 & & & & & & \\
\hline PSEA10 & .50 & .37 & .52 & .23 & .30 & .16 & .23 & .28 & .49 & & & & & \\
\hline PSEA11 & .63 & .35 & .47 & .48 & .52 & .52 & .48 & .49 & .54 & .34 & & & & \\
\hline PSEA12 & .45 & .30 & .27 & .30 & .34 & .38 & . 40 & .27 & .55 & .33 & .50 & & & \\
\hline PSEA13 & .03 & .24 & .18 & . 16 & . 12 & .35 & .20 & .10 & .21 & .02 & .23 & .21 & & \\
\hline PSEA14 & .73 & .45 & .41 & .81 & .63 & .67 & .60 & .42 & .50 & .33 & .64 & .40 & .34 & \\
\hline PSEA15 & .44 & .42 & .50 & .42 & .43 & .39 & .35 & .36 & .55 & .42 & .44 & .47 & .28 & .52 \\
\hline
\end{tabular}

Note. PSEA refers to the Police Self-Efficacy for Autism (PSEA) scale. Table 9 provides the actual item phrasing. 


\section{Appendix G}

Polychoric Correlation Matrix for the PSEA Items in Phase 2

\begin{tabular}{|c|c|c|c|c|c|c|c|c|c|c|c|c|}
\hline & PSEA1 & PSEA2 & PSEA3 & PSEA4 & PSEA5 & PSEA6 & PSEA7 & PSEA8 & PSEA9 & PSEA10 & PSEA11 & PSEA12 \\
\hline PSEA2 & .48 & & & & & & & & & & & \\
\hline PSEA3 & .52 & .82 & & & & & & & & & & \\
\hline PSEA4 & .69 & .43 & .41 & & & & & & & & & \\
\hline PSEA5 & .59 & .37 & .42 & .51 & & & & & & & & \\
\hline PSEA6 & .48 & .28 & .40 & .37 & .60 & & & & & & & \\
\hline PSEA7 & .50 & .57 & .58 & .56 & .40 & .31 & & & & & & \\
\hline PSEA8 & .62 & .64 & .56 & .45 & .35 & .41 & .59 & & & & & \\
\hline PSEA9 & .57 & .51 & .45 & .51 & .50 & .35 & .52 & .57 & & & & \\
\hline PSEA10 & .59 & .44 & .48 & .44 & .30 & .31 & .54 & .47 & .51 & & & \\
\hline PSEA11 & .40 & .53 & .53 & .35 & .45 & .30 & .51 & .45 & .50 & .37 & & \\
\hline PSEA12 & .66 & .43 & .42 & .70 & .57 & .32 & .50 & .44 & .56 & .48 & .42 & \\
\hline PSEA13 & .58 & .60 & .53 & .50 & .42 & .34 & .57 & .63 & .58 & .46 & .45 & .51 \\
\hline
\end{tabular}

Note. PSEA refers to the Police Self-Efficacy for Autism (PSEA) scale. Table 9 provides the actual item phrasing. 
POLICE SELF-EFFICACY

\section{Appendix $\mathbf{H}$}

The Police Self-Efficacy for Autism (PSEA) Scale: Phase 2

The following items are designed to help us understand more about what might be difficult for a police officer when working with a person with autism on the job. We are interested in your own personal judgments, so please answer by considering your own capabilities at this point in your career as a police officer.

When working as a police officer ...

PSEA1 I can identify some signs of autism when I observe them

PSEA2 I can de-escalate a situation in which a person with autism is harming others.

PSEA3 I can de-escalate a situation in which a person with autism is harming himself or herself.

PSEA4 I can explain at least three general characteristics of a person with autism to another police officer who asks.

PSEA5 I can distinguish autism from other disabilities.

PSEA6 I can tell the difference between someone who has autism and someone who is demonstrating drug-induced behavior.

PSEA7 I can adapt the way I communicate to explain something to a person with autism.

PSEA8 I can establish rapport with someone who has autism.

PSEA9 I can use what I know about autism to help find an individual with autism who has become a missing person.

PSEA10 I can seek appropriate information from a caregiver when trying to learn more about someone with autism.

PSEA11 I can gather identifying information from someone with autism who does not use verbal speech.

PSEA12 I can inform a concerned citizen about autism.

PSEA13 I can modify the environment to help an individual with autism feel calm during an emergency.

\section{Response Format}

I cannot do that I doubt I can do that I'm fairly certain I can do that I can do that


POLICE OFFICER SELF-EFFICACY

\section{References}

American Educational Research Association (AERA), American Psychological Association (APA), \& National Council on Measurement in Education (NCME). (2014). Standards for Educational and Psychological Testing. Washington, DC: American Educational Research Association.

American Psychiatric Association. (2013). Diagnostic and statistical manual of mental disorders (5th ed.). Arlington, VA: Author.

Anshel, M. H. (2000). A conceptual model and implications for coping with stressful events in police work. Criminal Justice and Behavior, 27, 375-400. doi: $10.1177 / 0093854800027003006$

Artino, A. R. (2012). Academic self-efficacy: From educational theory to instructional practice. Perspectives on Medical Education, 1, 76-85. doi:10.1007/s40037-012$0012-5$

Bahora, M., Hanafi, S., Chien, V. H., \& Compton, M. T. (2008). Preliminary evidence of effects of Crisis Intervention Team training on self-efficacy and social distance. Administration and Policy in Mental Health, 35, 159-167. doi:10.1007/s10488007-0153-8

Bailey, A., Barr, O., \& Bunting, B. (2001). Police attitudes toward people with intellectual disability: An evaluation of awareness training. Journal of Intellectual Disability Research, 45, 344-350. doi:10.1046/j.1365-2788.2001.00339.x

Bakare, M. O., Ebigbo, P. O., Agomoh, A. O., \& Menkiti, N. C. (2008). Knowledge About Childhood Autism Among Health Workers (KCAHW) questionnaire: 


\section{POLICE OFFICER SELF-EFFICACY}

Description, reliability and internal consistency. Clinical Practice and Epidemiology in Mental Health, 4(17), 1-8. doi:10.1186/1745-0179-4-17

Baio, J., Wiggins, L., Christensen, D. L., Maenner, M. J., Daniels, J., Warren, Z., ... Pettygrove, S. (2018). Prevalence of Autism Spectrum Disorder among children aged 8 years -- Autism and developmental disabilities monitoring network, 11 sites, United States, 2014. MMWR Surveillance Summaries, 67(6), 1-23. doi: 10.15585/mmwr.ss6706a1

Bandura, A. (1986). Social foundations of thought and action: A social cognitive theory. Englewood Cliffs, NJ: Prentice-Hall.

Bandura, A. (1997). Self-efficacy: The exercise of control. New York, NY: W. H. Freeman and Company.

Bandura, A. (2006). Guide for constructing self-efficacy scales. In F. Pajares \& T. Urdan (Eds.). Self-efficacy beliefs of adolescents (Vol. 5, pp. 307-337). Greenwich, CT: Information Age Publishing.

Beatty, P. C., \& Willis, G. B. (2007). Research synthesis: The practice of cognitive interviewing. Public Opinion Quarterly, 71, 287-311. doi:10.1093/poq/nfm006

Bond, T. G., \& Fox, C. M. (2015). Applying the Rasch model: Fundamental measurements in the human sciences. 3rd ed., NJ: Routledge.

Broussard, B., Krishan, S., Hankerson-Dyson, D., Husbands, L., Stewart-Hutto, T., \& Compton, M. T. (2011). Development and initial reliability and validity of four self-report measures used in research on interactions between police officers and individuals with mental illnesses. Psychiatry Research, 189, 458-462. doi:10.1916/j.psychres.2011.06.017 


\section{POLICE OFFICER SELF-EFFICACY}

Brouwers, A., \& Tomic, W. (2001). The factorial validity of scores on The Teacher Interpersonal Self-efficacy Scale. Educational and Psychological Measurement, 61, 433-445. doi:10.1177/00131640121971301

Burke, R. J. (1993). Work-family stress, conflict, coping, and burnout in police officers. Stress Medicine, 9, 171-180. doi:10.1002/smi.2460090308

Cattell, R. B. (1966). The scree test for the number of factors. Multivariate Behavioral Research, 1, 245-276. doi:10.1207/s15327906mbr0102_10

Centers for Disease Control and Prevention. (2018). Autism spectrum disorder data and statistics: Prevalence. Retrieved from https://www.cdc.gov/ncbddd/autis $\mathrm{m} /$ data.html

Chappell, A. T. (2007). Police academy training: Comparing across curricula. Policing: An International Journal of Police Strategies \& Management, 31, 36-56. doi:10.1108/13639510810852567

Chown, N. (2009). 'Do you have any difficulties that I may not be aware of?' A study of autism awareness and understanding in the UK police service. International Journal of Police Science \& Management, 12, 256-273. doi:10.1350/ijps.201 0.12 .2 .174

Çokluk, Ö., \& Koçak, D. (2016). Using Horn's parallel analysis method in exploratory factor analysis for determining the number of factors. Educational Sciences: Theory and Practice, 16, 537-551. doi:10.12738/estp.2016.2.0328 


\section{POLICE OFFICER SELF-EFFICACY}

Copenhaver, A., \& Tewksbury, R. (2018). Interactions between autistic individuals and law enforcement: A mixed-methods exploratory study. American Journal of Criminal Justice, 44, 309-333. doi:10.1007/s12103-018-9452-8

Corona, L. L., Christodulu, K. V., \& Rinaldi, M. L. (2017). Investigation of school professionals' self-efficacy for working with students with ASD: Impact of prior experience, knowledge, and training. Journal of Positive Behavior Interventions, 19, 90-101. doi:10.1177/1098300716667604

Costello, A. B., \& Osborne, J. W. (2005). Best practices in exploratory factor analysis: Four recommendations for getting the most from your analysis. Practical Assessment, Research \& Evaluation, 10, 1-9. Retrieved from http://pareonline.net/getvn.a sp?v=10\&n=7

Crane, L., Maras, K., Hawken, T., Mulcahy, S., \& Memon, A. (2016). Experiences of autism spectrum disorder and policing in England and Wales: Surveying police and the autism community. Journal of Autism and Developmental Disorders, 46, 2028-2041. doi:10.1007/s10803-016-2729-1

Debbaudt, D., \& Rothman, D. (2001). Contact with individuals with autism. FBI Law Enforcement Bulletin, 70, 20-24. doi:10.1037/e312842004-005

Department of Justice. (2010). Americans with disabilities act: Title II regulations. Civil Rights Division. Retrieved from http://www.ada.gov

DeVellis, R. F. (2012). Scale development: Theory and applications. Los Angeles, CA: Sage. 


\section{POLICE OFFICER SELF-EFFICACY}

Fan, W., \& Yan, Z. (2010). Factors affecting response rates of the web survey: A systematic review. Computers in Human Behavior, 26, 132-139. doi:10.1016/j.chb.20 09.10.015

Fida, R., Laschinger, H. K. S., \& Leiter, M. P. (2018). The protective role of self-efficacy against workplace incivility and burnout in nursing: A time-lagged study. Health Care Management Review, 43, 21-29. doi:10.1097/HMR.0000000000000126

Gardner, L. B., Campbell, J. M., \& Westdal, J. (2018). Descriptive analysis of law enforcement officers' experiences with and knowledge of autism. Journal of Autism and Developmental Disorders, 49, 1278-1283. doi:10.1007/s10803-018$3794-4$

Hair, J. F., Black, W. C., Babin, B. J., Anderson, R. E., \& Tatham, R. L. (1998). Multivariate data analysis (Vol. 5). Upper Saddle River, NJ: Prentice Hall.

Harrell, E. (2017). Crime against persons with disabilities, 2009-2015. U.S. Department of Justice, Office of Justice Programs, Bureau of Justice Statistics. Retrieved from https://www.bjs.gov/content/pub/pdf/capd0915st.pdf.

Harrison, A. J., Bradshaw, L. P., Naqvi, N. C., Paff, M. L., \& Campbell, J. M. (2017). Development and psychometric evaluation of the Autism Stigma and Knowledge Questionnaire (ASK-Q). Journal of Autism and Developmental Disorders, 47, 3281-3295. doi:10.1007/s10803-017-3242-x

Harrison, A. J., Slane, M. M., Hoang, L., \& Campbell, J. M. (2016). An international review of autism knowledge assessment measures. Autism,21, 262-275. doi:10.1177/1362 361316638786 


\section{POLICE OFFICER SELF-EFFICACY}

Henshaw, M., \& Thomas, S. (2012). Police encounters with people with intellectual disability: Prevalence, characteristics and challenges. Journal of Intellectual Disability Research, 56, 620-631.doi:10.1207/S15328007SEM1001_6

Helsel, P. (2017). Parents demand answers after autistic boy held on ground by officer. Retrieved from NBC News website: https:/www.nbcnews.com/news/usnews/parents-demand-answers-after-autistic-boy-held-ground-officer-n802801

Henson, R. K., \& Roberts, R. K. (2006). Use of exploratory factor analysis in published research: Common errors and some comment on improved practice. Educational and Psychological Measurement, 66, 393-416. doi:10.1177/0013164405282 485

Horn, J. L. (1965). A rationale and test for the number of factors in factor analysis.

Psychometrika, 30, 179-185. doi:10.1016/j.jrurstud.2015.12.005

Kline, P. (1986). Making tests reliable II: Personality inventories. In P. Kline (Ed), $A$ handbook of test construction: Introduction to psychometric design (pp. 59-76). London, United Kingdom: Methuen.

Kline, R. B. (2016). Principles and practice of structural equation modeling (4th ed.). New York, NY: The Guilford Press.

Lauermann, F., \& König, J. (2016). Teachers' professional competence and wellbeing: Understanding the links between general pedagogical knowledge, self-efficacy and burnout. Learning and Instruction, 45, 9-19. doi:10.1016/j.learninstruc.201 6.06 .006

Linacre, J.M. (2016). Winsteps ${ }^{\circledR}$ (Version 3.70.0) [Computer Software]. Beaverton, Oregon: Winsteps.com. Retrieved from http://www.winsteps.com/ 


\section{POLICE OFFICER SELF-EFFICACY}

Linacre, J. M. (2019). WINSTEPS Rasch-Model computer programs (Manual 4.4.1). Chicago: Winsteps.com.

Louisville Metro Police Department. (2019). Mission and values. Retrieved from https://www.louisville-police.org/.

Love, A. M. A., Findley, J. A., Ruble, L. A., \& McGrew, J. H. (2019). Teacher selfefficacy for teaching students with autism spectrum disorder: Associations with stress, teacher engagement, and student IEP outcomes following COMPASS consultation. Focus on Autism and Other Developmental Disabilities. doi:1088357619836767.

Love, A. M. A., Toland, M. D., Usher, E. L., Campbell, J. M., \& Spriggs, A. D. (2019). Can I teach students with Autism Spectrum Disorder?: Investigating teacher selfefficacy with an emerging population of students. Research in Developmental Disabilities, 89, 41-50. doi: 10.1016/j.ridd.2019.02.005

Magaña, S., Lopez, K., Aguinaga, A., \& Morton, H. (2013). Access to diagnosis and treatment services among Latino children with autism spectrum disorders. Intellectual and Developmental Disabilities, 51, 141-152. doi:10.1352/1934$9556-51.3 .141$

McCarty, W. P., Aldirawi, H., Dewald, S., \& Palacios, M. (2019). Burnout in Blue: An analysis of the extent and primary predictors of burnout among law enforcement officers in the United States. Police Quarterly. Retrieved from https://journals.sagepub.com/doi/abs/ 10.1177/1098611119828038.

McDonald, R. P. (1999). Test theory: A unified treatment. NY: Lawrence Erlbaum Associates. 


\section{POLICE OFFICER SELF-EFFICACY}

McKeever, B. W. (2013). News framing of autism: Understanding media advocacy and the Combating Autism Act. Science Communication, 35, 213-240. doi:10.1177/1075547012450951

Muthén, L. K., \& Muthén, B. O. (2005). Mplus: Statistical analysis with latent variables: User's guide. Los Angeles: Muthén \& Muthén.

Nagib, W., \& Williams, A. (2017). Toward an autism-friendly home environment. Housing Studies, 32, 140-167. doi:10.1080/02673037.201 6.1181719

Organization for Autism Research. (2014). Life journey through autism: A guide to safety. Arlington, VA: Author.

Ortoleva, S. (2010). Inaccessible justice: Human rights, persons with disabilities and the legal system. ILSA Journal of International and Comparative Law, 17, 281-320.

Pellicano, E., Dinsmore, A., \& Charman, T. (2014). What should autism research focus upon? Community views and priorities from the United Kingdom. Autism, 18, 756-770. doi:10.1177/1362361314529627

Peterson, C. H., Peterson, N. A., \& Powell, K. G. (2017). Cognitive interviewing for item development: Validity evidence based on content and response processes. Measurement and Evaluation in Counseling and Development, 50(4), 217-223. doi:10.1080/07481756.2017.1339564

Preece, D. (2003). Providing an 'autism-friendly' service for children with an autistic spectrum disorder in a short-term (respite) care setting. Journal of Integrated Care, 11(1), 39-44. doi:10.1108/14769018200300009 


\section{POLICE OFFICER SELF-EFFICACY}

Rava, R., Shattuck, P., Rast, J., \& Roux, A. (2017). The prevalence and correlates of involvement in the criminal justice system among youth on the autism spectrum. Journal of Autism and Developmental Disorders, 47, 340-346. doi:10.1007/s10803-016-2958-3

Rice, C. E., Zablotsky, B., Avila, R. M., Colpe, L. J., Schieve, L. A., Pringle, B., \& Blumberg, S. J. (2016). Reported wandering behavior among children with autism spectrum disorder and/or intellectual disability. The Journal of Pediatrics, 174, 232-239. doi:10.1016/j.jpeds.2016.03.047

Rimal, R. N. (2000). Closing the knowledge-behavior gap in health promotion: The mediating role of self-efficacy. Health Communication, 12, 219-237. doi:10.1207/S15327027HC1203_01

Rubio, D. M., Berg-Weger, M., Tebb, S. S., Lee, E. S., \& Rauch, S. (2003). Objectifying content validity: Conducting a content validity study in social work research. Social Work Research, 27(2), 94-104. doi:10.1093/swr/27.2.94

Ruble, L. A., Toland, M. D., Birdwhistell, J. L., McGrew, J. H., \& Usher, E. L.(2013). Preliminary study of the autism self-efficacy scale for teachers. Research in Autism Spectrum Disorders, 7, 1151-1159. doi:10.1016/j.rasd.201306.006

Schwarzer, R., \& Hallum, S. (2008). Perceived teacher self-efficacy as a predictor of job stress and burnout: Mediation analyses. Applied Psychology: An International Review, 57, 152-171. doi:10.1111/j.1464-0597.2008.00359.x

Sheehan, K. B. (2001). E-mail survey response rates: A review. Journal of ComputerMediated Communication, 6. doi:10.1111/j.10836101.2001.tb00117.x 


\section{POLICE OFFICER SELF-EFFICACY}

Sheeran, P., Maki, A., Montanaro, E., Avishai-Yitshak, A., Bryan, A., Klein, W. M., ... \& Rothman, A. J. (2016). The impact of changing attitudes, norms, and self-efficacy on health-related intentions and behavior: a meta-analysis. Health Psychology, 35, 1178

Silberman, S. (2017). The police need to understand autism. Retrieved from The New York Times website https://www.nytimes.com/2017/09/19/opinion/police-autismunderstanding.html

Skinner, B. F. (1984). The evolution of behavior. Journal of Experimental Analysis of Behavior, 41, 217.

Stevens, J. P. (1992). Applied multivariate statistics for the social sciences (2nd edition). Hillsdale, NJ: Erlbaum.

Tabachnick, B. G., \& Fidell, L. S. (2007). Using multivariate statistics. Boston, MA: W. H. Freeman and Company.

Teagardin, J., Dixon, D. R., Smith, M. N., \& Granpeesheh, D. (2012). Randomized trial of law enforcement training on autism spectrum disorder. Research in Autism Spectrum Disorders, 6, 1113-118. doi:10.1016/j.rasd.2012.02.002

Thorndike, R. M., \& Thorndike-Christ, T. (2010). Measurement and evaluation in psychology and education. Boston, MA: Prentice Hall.

Williams, B., Brown, T., \& Onsman, A. (2012). Exploratory factor analysis: A five-step guide for novices. Australasian Journal of Paramedicine, 8, 1-12. doi:10.33151/ajp.8.3.93

Willis, G. B. (1999). Cognitive interviewing: A “how to” guide. Research Triangle Institute. Retrieved from http://www.uiowa.edu/ c07b209/interview.pdf 


\section{POLICE OFFICER SELF-EFFICACY}

Zee, M., \& Koomen, H. M. (2016). Teacher self-efficacy and its effects on classroom processes, student academic adjustment, and teacher well-being: A synthesis of 40 years of research. Review of Educational Research, 86(4), 981-1015. doi:10.3102/00346543

Zee, M., Koomen, H. M. Y., Jellesma, F. C., Geerlings, J., \& de Jong, P. F. (2016). Interand intra- individual differences in teachers' self-efficacy: A multilevel factor exploration. Journal of School Psychology, 55, 39-56.

doi:10.1016/j.jsp.2015.12.003 


\section{Vita}

\section{Education:}

April 2017

May 2016

December 2010 Bachelor of Science, Education, Eastern Kentucky University

\section{Awards:}

Lexington Police: Distinguished Service Award for Significant Acts of Outstanding Character (June, 2017)

UK Inclusive Excellence Award (April, 2017)

UK Center for Graduate and Professional Diversity Initiatives Award (April, 2017)

Mind \& Life Summer Research Institute Research Fellow Scholarship (June, 2016)

UK College of Education: Teacher Who Made a Difference Award (April, 2015)

\section{External Funding:}

Autism Society of the Bluegrass, Community Service Grants $(\$ 1,000 ; 2016-2018)$

Arvle and Ellen Turner Thacker Research Dissertation Grant $(\$ 2,000 ; 2018-2019)$

Local Impact Grant Recipient, Autism Speaks (\$5,000; 2018-2019)

LGBTQ* Endowment Scholarship (\$2,000; 2018-2019)

Kentucky Autism Training Center Partnership Grant (\$21,600; 2018-2019)

\section{Publications:}

Ruble, L. A., \& Love, A. M. A. (in press). Supports for students with Autism Spectrum Disorder. Routledge Encyclopedia of Education.

Love, A. M. A., \& Hale, K. (in press). Support for Deaf students and those with hearing impairments. Routledge Encyclopedia of Education.

Love, A. M. A., Toland, M. D., Usher, E., L., Campbell, J. M., \& Spriggs, A. D. (2019). Can I teach students with autism spectrum disorder?: Investigating teacher selfefficacy within an emerging population of students. Research in Developmental Disorders.

Love, A. M. A., Findley, J. A., \& Ruble, L. A., McGrew, J. H. (2019). Teacher selfefficacy for teaching students with autism spectrum disorder: Associations with stress, teacher engagement, and student IEP outcomes. Focus on Autism And Other Developmental Disabilities. Retrieved from

Love, A. M. A., Butz, A. R., Usher, E. L., \& Waiters, B. L. (2018). Open-ended responses from early adolescents: Method matters. Journal of Adolescence, 67, 31-34. doi: 10.1016/j.ad olescence.2018.05.007

Dueber, D., Love, A. M. A., Toland, M. D., \& Douin, T. A. (2017). Comparison of single-response format and forced-choice format instruments using Thurstonian item response theory. Educational and Psychological Measurement. 1-21. doi: 0013164417752782

Jones, M. H., Hershberger, M. A., Goodrich, K. M., Hackel, T. S., \& Love, A. M. A. (under review). Preservice teachers' self-efficacy for teaching LGBQ youth. Journal of Teacher Education. 
Railey, K. S., Love, A. M. A, \& Campbell, J. M. (under review). A systematic review of law enforcement officer training related to autism spectrum disorder. Focus on Autism and Other Developmental Disabilities.

Ruble, L. A., Love, A. M. A., \& McGrew, J. H. (under review). A common elements approach for teaching students with Autism Spectrum Disorder. Research in Autism Spectrum Disorders. 